\title{
CESSATION OF ENVIRONMENTALLY-ASSISTED CRACKING IN A LOW-ALLOY STEEL: THEORETICAL ANALYSIS
}

RECEIVED

G. L. Wire

JAN 281997

U. S. Department of Energy Contract DE-AC11-93PN 38195

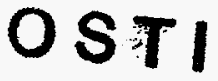

$$
\text { WAPD }-T-3126
$$

\section{DISCLAIMER}

This report was prepared as an account of work sponsored by an agency of the United States Government. Neither the United States Government nor any agency thereof, nor any of their employees, makes any warranty, express or implied, or assumes any legal liability or responsibility for the accuracy, completeness, or usefulness of any information, apparatus, product, or process disclosed, or represents that its use would not infringe privately owned rights. Reference herein to any specific commercial product, process, or service by trade name, trademark, manufacturer, or otherwise does not necessarily constitute or imply its endorsement, recommendation, or favoring by the United States Government or any agency thereof. The views and opinions of authors expressed herein do not necessarily state or reflect those of the United States Government or any agency thereof.

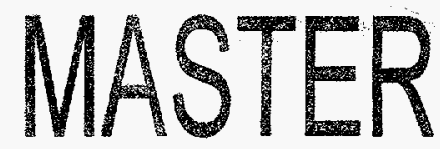

\section{ASME PRESSURE VESSELS AND PIPING CONFERENCE}

\author{
July 27-31, 1997, The Peabody Hotel \\ ORLANDO, FLORIDA
}

NOTICE
This report was prepared as an account of work sponsored by the United States
Government. Neither the United States, nor the United States Department of Energy, nor
any of their employees, nor any of their contractors, subcontractors, or their employees,
make any warranty, express of implied, or assumes any legal liability or responsibility for
the accuracy, completeness or usefulness of any information, apparatus, product or
process disclosed, or represents that its use would not infringe privately owned rights.

\section{HH \\ DASTRIBUTION OF THIS DOCUMENT IS UNLIMITED}




\section{DISCLAIMER}

Portions of this document may be illegible in electronic image products. Images are produced from the best available original document. 


\title{
CESSATION OF ENVIRONMENTALLY-ASSISTED \\ CRACKING IN A LOW-ALLOY STEEL: \\ THEORETICAL ANALYSIS
}

\author{
G. L. Wire \\ Westinghouse Electric Corporation \\ West Miffiln, PA 15122-0079
}

\section{ABSTRACT}

Environmentally Assisted Cracking (EAC) can cause increases in fatigue crack growth rates of 40 to 100 times the rate in air for low alloy steels. The increased rates can lead to very large predicted crack growth. EAC is activated by a critical level of dissolved sulfides at the crack tip. Sulfide inclusions (MnS) in the steel produce corrosive sulfides in solution following exposure by a growing crack. In stagnant, low oxygen water conditions considered here, diffusion is the dominant mass transport mechanism acting to change the sulfide concentration within the crack.

Previous diffusion analysis and experimental work (Wire and $\mathrm{Li}, 1996$ ) has shown that surface cracks will not initiate EAC for most loading conditions. The average crack tip velocity is below the level required to produce the critical crack tip sulfide ion concentration required for EAC. Crack extension analyses also consider the breakthrough of large, hypothetical embedded defects with the attendant large freshly exposed sulfide inventory. Combrade et al. (1988) noted that a large inventory of undissolved metallurgical sulfides on crack flanks could trigger EAC, but did not quantify the effects.

Diffusion analysis is extended herein to cover breakthrough of embedded defects with large sulfide inventories. The mass transport via diffusion is limited by the sulfide solubility. As a result, deep cracks in high sulfur steels are predicted to retain undissolved sulfides for extended but finite periods of time $t_{\text {diss }}$ which increase with the crack length and the metallurgical sulfide content in the steel. The analysis shows that the duration of EAC is limited to $t_{\text {diss }}$ providing $V_{\text {oac }}$, the crack tip velocity associated with EAC is less than $V_{\text {In }}$, the crack tip velocity below which EAC will not occur in an initially sulfide free crack. This condition on $V_{\text {esc }}$ need only be met for a short time following crack cleanup to turn off EAC. The predicted crack extension due to limited duration of EAC is a small fraction of the initial embedded defect size and would not greatly change calculated crack depths.

\section{BACKGROUND}

Environmentally Assisted Cracking (EAC) causes increases in fatigue crack growth rates of 40 to 100 times the rate in air for low alloy steels. This large increase leads to large predicted crack growth. Excellent reviews of fatigue crack growth in low alloy steels have been recently performed by Scott (1988) and James (1995). Only the points essential for this work are discussed. EAC is activated by a critical level of dissolved sulfides at the crack tip. Sulfide inclusions (MnS) in the steel dissolve to produce corrosive sulfides in solution following exposure by a growing crack. In stagnant, low oxygen environments considered in this work, Combrade et al. (1988) showed that diffusion is the main mass transport mechanism acting to change the sulfide concentration within the crack.

Wire and $\mathrm{Li}$ (1996) performed tests and diffusion analysis to show that surface cracks which are initially clean of sulfides will not initiate EAC for most loading conditions. The average crack tip velocity for most applications is not high enough to develop the critical sulfide concentration required for EAC. Further, even crack tip velocities above the critical initiation velocity of 
$V_{\text {in }}=5 E-07 \mathrm{~mm} / \mathrm{s}$ for a crack length of 2.5 $\mathrm{mm}$ in high sulfur steels would not initiate $E A C$ in a surface crack unless a series of closely spaced transients exceeded a total crack extension of over $0.33 \mathrm{~mm}$.

However, life assessment analyses also consider the breakthrough of a large embedded defect with a large sulfide inventory. If such defects break through to the surface in mid to late life, the attendant metallurgical sulfide inventory may be sufficiently large to activate EAC even at low cycling rates. Past laboratory tests by James (1994) on high sulfur plate material specimens with large sulfide inventories suggested that EAC can persist down to the lowest measured velocity of $4 E-08 \mathrm{~mm} / \mathrm{s}$ and times of over 1000 hours. The data showed only a hint that the phenomena would cease at 243C (see Figure 1). These tests raised the concern that breakthrough of an embedded defect in a high sulfur steel would lead to indefinite periods of high crack growth rates. However, these tests were highly accelerated, with extensive periods of continuous cycling at crack growth rates of $160 \mathrm{~mm} /$ year.

These concerns were resolved by tests performed recently $(\mathrm{Li}, 1997)$ and analyzed herein. These tests directly simulated an embedded defect breakthrough with a large sulfide inventory. The tests had more realistic cycling rates with interrupted cycling as low as once per hour. The tests showed that EAC does cease after 100-1000 hours for cracks with an initial depth of 2.5-10 mm. However, the diffusion time constants for these crack depths are only a few hours, and sulfide dissolution on corrosion coupons (Kuniya, et. al., 1992) was observed to take only a day or two. Therefore the persistence of EAC to 1000 hours might appear to represent a contradiction. It will be shown that low sulfide solubility extends the crack cleanup times considerably, and that the results by $L i$ (1997) can be predicted by diffusion theory.

Large sulfides can last over two days at crack tips even in initially clean cracks as observed by Wire and Li (1996). High sulfur
A302B steels $(0.025 \%$ S) starting with an air precrack of $2.5 \mathrm{~mm}$ length can sustain EAC conditions for over one week without significant additional crack extension, due to sluggish sulfide dissolution. Further evidence of sluggish sulfide dissolution is provided by delays of over thirty hours in starting EAC in initially sulfide free cracks at high crack growth rates.

Wire and Li (1996) modeled EAC initiation with sluggish sulfide dissolution by extending Combrade's (1988) steady state analysis to transient conditions. A simplified summary of the transient analysis is shown schematically in Figure 2. Definitions of key parameters are given in Table 1.

The concentration is determined by a simple one dimensional balance of sulfur production at a flux of $F$ at the crack tip and diffusion to the crack mouth. The concentration $C$ decreases with distance $x$ according to

$$
F=-D \frac{d C}{d x}
$$

where $D$ is the diffusion constant. For $C=0$ at a distance a from the source this leads to

$$
\mathrm{C}=\mathrm{F} \text { a/D at the crack tip. }
$$

For crack growth starting at time $=0$, the transient flux of sulfides was shown to be

$$
\mathrm{F}=\mathrm{H} \Delta \mathrm{a} / \tau, \mathrm{t}<\tau
$$

where $H$ is the quantity of metallurgical sulfides exposed by the advancing crack, $\Delta a$ is the crack extension, and $\tau$ is the sulfide dissolution time.

For small crack extensions, Eqn. 3a shows the transient sulfide flux buildup is sensibly proportional to the crack extension. This shows that the flux would be expected to be very small for a few cycles of crack extension. EAC initiation would thus not be expected for a few cycles of crack extension. The flux buildup will continue until particles formed at the first cycle are 
dissolved away, i.e. until $t=r$, the particle dissolution time. The flux reaches a maximum value of

$$
F_{\max }=\frac{\mathrm{Hda} / \mathrm{dN}}{T}=\mathrm{HV}, \mathrm{t} \geq r
$$

where $V$ is the crack tip velocity.

The transient analysis showed that for EAC to initiate, a critical minimum velocity $V_{\text {in }}$ and a minimum crack extension $\Delta \mathbf{a}$ were required.

Using the relationship

$$
V_{\text {in }}=D C_{c r t t} / H a
$$

from combining Equations 2 and 3b, a quantitative comparison was made with the observed critical velocities. Using the critical sulfur concentration of $3 \mathrm{ppm}$ for $\mathrm{EAC}$, and values of $\mathrm{H}$ consistent with Combrade et al. (1988), the observed minimum critical velocity of $5 E-07 \mathrm{~mm} / \mathrm{s}$ in a $3 \mathrm{~mm}$ crack could be explained. Equations 2 and $3 a$ were used to predict the minimum crack extension required for EAC initiation. Scanning Electron Microscopy (SEM) examinations were done on the $A 302 B$ crack faces, after removal of the oxide layer. Partially dissolved metallurgical sulfides were observed behind the crack tip for a maximum soak time after exposure of 58 hours. Using 2.4 days observed for sulfide survival led to $\Delta a$ predicted of $0.4 \mathrm{~mm}$, which is in good agreement with experimental minimum of $0.33 \mathrm{~mm}$ for the high sulfur A302B.

\section{BASIS FOR DIFFUSION ANALYSIS}

The technical basis for sulfide solubility being very low is developed in this section and the diffusion equation is modified to handle limited solubility. Section 3 solves the diffusion equation for the realistic case including time and spatial dependence.

\subsection{Unlimited Sulfide Solubility Leads to Contradiction}

The assumption of unlimited sulfide solubility is shown in this subsection to contradict theoretical and experimental results on EAC.

Analysis for the case of sulfide concentration in the presence of a large inventory of sulfides requires solution of the diffusion equation with an extended source term. This analysis presumes that sulfide solubility is not limited, and that all sulfide particles in the metal would begin dissolving at a rate proportional to $k_{1} \exp \left(-k_{1} t\right)$. The parameter $k_{1}$ is a sulfide dissolution rate constant, and the exponential term is a convenient method to incorporate the finite lifetime of a sulfide particle. This relationship presumes sulfide dissolution times are independent of the local environment. Definitions of key parameters are provided in Table 1 . The above assumptions lead to the following differential equation describing the sulfide ion concentration at the crack tip:

$$
\frac{\partial C}{\partial t}=\frac{D \partial^{2} C}{\partial x^{2}}+H k_{1} \exp \left(-k_{1} t\right)
$$

where $D, C$, and $H$ are as in Eqn. 1-4.

Carslaw and Yaeger (1959) have developed the solution to Equation 5 . This equation also arises for heat transfer from a heat source which is exponential in time with zero temperature at both ends of a sheet $=1$ in length. The solution is extended to the present case by substituting $a=1 / 2$ and substituting diffusion constants for the heat transfer constants. The result at the crack tip is

$$
\begin{aligned}
& C=H \frac{\left(1-\cos \left(\pi / 2 \sqrt{k_{1} / k_{2}}\right)\right) \exp \left(-k_{1} t\right)}{\cos \left(\pi / 2 \sqrt{\left.k_{1} / k_{2}\right)}\right.} \\
& \frac{-4 H}{\pi} \sum_{n} \frac{(-1)^{n} \exp \left(-(2 n+1)^{2} k_{2} t\right)}{(2 n+1)\left[(2 n+1)^{2} k_{2} / k_{1}-1\right]}
\end{aligned}
$$

where $k_{1}$ must not be equal to $k_{2}(2 n+1)^{2}$ and $k_{2}$ is the diffusion "rate" $k_{2}=\pi^{2} \mathrm{D} / 4 \mathrm{a}^{2}$. 
For the relatively sluggish sulfide dissolution observed for $\mathrm{A} 302 \mathrm{~B}$, the predicted sulfide concentration at the crack tip would quickly rise to a maximum level of

$$
\begin{aligned}
C & =\frac{\pi^{2}}{8} k_{1} / k_{2} H \exp \left(-k_{1} t\right) \\
& =H k_{1} a^{2} \exp \left(-k_{1} t\right) / 2 D,\left(k_{1} / k_{2}<<1\right) .(7)
\end{aligned}
$$

This formulation predicts that deeper cracks (lower $k_{2}$ ) would lead to increasingly high sulfide ion concentrations, rising to a maximum value of $\mathrm{Hk}_{1} \mathrm{a}^{2} / 2 \mathrm{D}$ at the crack tip. The quantity $\mathrm{H}$ expresses the amount of sulfides exposed on the crack and can be written as

$$
H=\frac{\rho_{s}}{\rho_{w}} \frac{d_{\text {eff }}}{d} \text { AF. }
$$

in Equation 8, AF is the sulfide area fraction, $\rho_{s} / \rho_{w}$ are the densities of sulfide in the particle and water respectively, $d$ is the crack opening and $d_{\text {eff }}$ is the effective distance over which sultides are exposed (Wire and $L i, 1996)$. The quantity $d_{\text {eff }}$ may be greater than $d$, allowing for cracking above and below the crack plane to expose additional sulfides.

A large, round robin study of sulfides in EAC test specimens from many laboratories was undertaken several years ago (James and Poskie, 1993). Representative results are provided in Table 2 (Wire and James, 1996). For A302B high sulfur plate the average value of AF is 0.0012 , so that the predicted sulfide concentration could reach a value of about $170 \mathrm{ppm}$ for a $1 \mathrm{~cm}$ crack even for the minimum $H$ with $d_{\text {eff }} / d=1$ and $k_{1}=1 / 10 \mathrm{hr}$. This value would become 1700 ppm for $d_{\text {eff }} / d=10$, and values of 20 for this parameter were required to fit test data on A302B (Wire and Li, 1996). The predicted value of $\mathrm{H}$ would only be a factor of six or so lower for medium sulfur forgings such as described in Table $2(0.008<\mathrm{S}<0.012 \%)$. Thus, this formulation suggests that sulfide concentrations would rise to very high levels in the tips of deep exposed cracks in a variety of steels. However, no EAC was observed in a recent test of medium sulfur steels $(0.011 \% \mathrm{~S})$ with an initial crack depth of $17 \mathrm{~mm}$ (James, et al., 1996) and in tests of compact tension specimens (Auten and Monter, 1995). This suggests that the sulfide ion concentration in cracks does not reach the theoretical limit from Eqn. 7. Therefore dissolution rates of sulfides in cracks must be reduced compared to open solutions.

Further evidence that high sulfide concentrations do not occur is available from direct testing. At levels of $\mathrm{H}_{2} \mathrm{~S}$ doping greater than 50 ppm, VanDerSluys (1993) observed that EAC persisted, even after flushing of the crack tip with clean water at the crack tip. Only subsequent flushing with $\mathrm{H}_{2} \mathrm{O}_{2}$ was able to turn off EAC. This implies that very stable FeS had been deposited on the crack flanks, and a very long term source of sulfide ions was now available (Combrade, 1990). The peroxide then oxidized the FeS, eliminating the source of dissolved sulfides. Since no such behavior has been observed in nondoped tests, it does not appear reasonable that the actual sulfide levels reach the maximum level from Eqn. 7.

\subsection{Experimental Evidence for Limited Solubility}

Manganese is a deliberate addition in low alloy steels to tie up almost all the sulfur in the form of MnS sulfides. The exposure of these sulfides by an advancing crack leads to dissolution of the MnS. The extremely low solubility of FeS and MnS at room temperature is well known, with solubility products of order $10^{-14}$ for MnS and $10^{-19}$ for FeS listed in standard handbooks (Weast, 1964). These low levels of sulfide solubility would lead to concentrations of sulfides below $1 \mathrm{ppm}$, and therefore below the reported critical minimum concentration to turn on EAC, about 3 ppm. However, solubility typically increases with increasing temperature, as dissociation is a thermally activated process, making the room temperature results of little value for current high temperature applications. 
Recently, solubility has been measured at higher temperatures in two separate tests. The measurements show higher solubility than at room temperature, but values are still limited. A summary of these results is provided in Table 3. The sulfides formed at high temperature transform to sulfates upon cooling to room temperature, where measurements can be made. IIli, et al., (1987), observed a maximum concentration of sulfate ions of $5.2 \mathrm{ppm}$ for $\mathrm{MnS}$ additions to deionized water in an A533B miniature autoclave exposed at $273 C$ for 25 days.

The sulfide concentration attainable from dissolution of MnS was limited by the solubility of MnS to values less than $50 \mathrm{ppm}$ in solutions of PWR water and pure water at 290C (Combrade, et al. (1989)). The solubility decreased with decreasing contents of $\mathrm{LOH}$ and boric acid, and was limited to less than $1 \mathrm{ppm}$ in the most dilute solution studied. The solubility of FeS was measured in the same test series. In cases where both were measured in the same chemistry the solubility of FeS was larger, and the authors concluded that dissolution of MnS would not lead to formation of FeS. It is noted that at under conditions where the Fe concentration is very high, e.g., low pH, Fes could be formed. Formation of FeS on the crack flanks would require higher sulfide levels, obtainable, for example, from the intentional injection of $\mathrm{H}_{2} \mathrm{~S}$ solutions performed by VanDerSluys. Another possibility would be concentration of sulfide ions by an electrochemical potential gradient, which could occur due to oxygen or chemical upsets. In low-oxygen water, however, the sulfide concentration in cracks would be limited by MnS solubility.

Andresen and Young (1995) directly measured sulfate levels of about $1 \mathrm{ppm}$ in crack tip water samples from a growing fatigue crack in A533B. This value increased to $4.9 \mathrm{ppm}$ with the ingress of oxygen into the bulk solution, and EAC turned on. More recently, levels of $12.1 \mathrm{ppm}$ sulfate maximum with oxygen ingress were observed by Young and Andresen using a lower volume sampling rate (1995). The above tests show that the solubility of MnS would be certainly less than $50 \mathrm{ppm}$, the maximum value in presence of high concentrations of $\mathrm{LiOH}$ and boric acid, and closer to the 5-10 ppm value observed in water with little or no $\mathrm{LiOH}$ and boric acid. Obviously, the solubility is greater than the minimum required to turn on EAC-about $3 \mathrm{ppm}$. This limited solubility must be accounted for in diffusion analysis. As is shown below, incorporation of this limit has profound effects on the estimated time for sulfide particles to dissolve and diffuse from the crack.

\subsection{Simple Point Source Calculation and Modified Diffusion Equation}

Simple point source calculations are performed to show the basis for modifying diffusion equations to account for reduced solubility. It is recognized that the $\mathrm{pH}$ and local electrochemical corrosion potential could vary with distance in a crack. The purpose of the analysis below is to assess the effects of limited sulfide solubility, which is valid over a range of $\mathrm{pH}$.

The maximum or saturation concentration of sulfides obtainable from dissolving metallurgical sulfides is defined to be $C_{s}$, which must evidently be greater than $\mathrm{C}_{\mathrm{crtt}}$, the minimum concentration of sulfide ions to turn on EAC at 243-288C. The physical situation is shown in Figure 3 for dissolution limited only by solubility, following the development of Cussler (1984). A spherical sulfide particle of radius $R_{0}$ dissolving in a large open volume of water produces a maximum possible flux of dissolving ions of $j=D C_{s} / R_{0}$ at the particle surface. This is a maximum flux with particle dissolution sufficiently rapid to saturate the solution at the particle surface. The dissolution rate over the total particle surface is then $4 \pi R_{0}{ }^{2}\left(D C_{s} / R_{0}\right)=4 \pi R_{0} D C_{s}$. Integration of this expression as the particle shrinks leads to the time of dissolution

$$
T=\left(\rho_{\mathrm{s}} / \rho_{\mathrm{w}}\right) \mathrm{R}_{\mathrm{o}}^{2} / 2 \mathrm{DC} \mathrm{C}_{\mathrm{s}}
$$

For a large sulfide particle of radius $30 \mu \mathrm{m}$, and $\mathrm{C}_{\mathrm{s}}$ assumed to be $5 \mathrm{ppm}$ for example, the calculated dissolution time in an open solution would only be 1.25 hours. A 
smaller sulfide of size $5 \mu \mathrm{m}$ would be predicted to dissolve in only 2 minutes. Dissolution rates as high as $1 \mu \mathrm{m} /$ minute at a $\mathrm{pH}$ of 4 can be inferred, based on data obtained by Pumphrey (1980). The calculated times are roughly consistent with the rapid dissolution of sulfides on open surfaces observed by Kuniya et al. (1992). Kuniya et al. observed that one half of the sulfides were dissolved on specimen surfaces after a rapid heatup to $288^{\circ} \mathrm{C}$ and immediate cooldown in an autoclave. The total time at high temperature was only about an hour. After 48 hours at high temperatures, all sulfides were dissolved.

Matsushima, et al. (1991), performed a study of sulfide dissolution in creviced and open steel specimens in oxygenated water at either 200 and $8000 \mathrm{ppb}$. They found that the high oxygen led to oxide films covering the sulfides outside the crevice. However, they claimed that behavior within crevices was representative of low oxygen conditions. They observed that over the 72 hour exposures that dissolution did not occur below $200 \mathrm{C}$, was only partial at $250 \mathrm{C}$, but was complete at $288 \mathrm{C}$. These results are of qualitative value, but for quantitative purposes only results in real cracks in low oxygen water will be used in this paper. Sulfides survived up to 58 hours or 2.4 days Wire and $\mathrm{Li}, 1996$ ) at the crack tip of high sulfur $A 302 B$ in tests designed to measure minimum crack tip velocities to turn on EAC. This suggests that the sulfide ion concentration may have been near $\mathrm{C}_{\mathrm{s}}$ and therefore dissolution was slowed. In contrast, no undissolved sulfides were located in a medium sulfur A508-2 forging subjected to about the same loading conditions. Since the medium sulfur steel contained some sulfides of significant size based on SEM examination of portions of a crack formed in air, it can be inferred that the actual dissolution of sulfides was more sluggish in the A302B.

If the solution has an initial concentration of sulfides $\mathrm{C}_{0}$, then the dissolution fluxes and times are changed dramatically. The flux at the particle surface now becomes $j=D\left(C_{s}-\right.$ $\left.C_{0}\right) / R_{0}$, reduced by the ratio $\left(C_{s}-C_{0}\right) / C_{s}$ from the case of a dilute solution. Dissolution rates decrease with increasing solution concentration and cease in a saturated solution. The corresponding dissolution time increases to

$$
\begin{aligned}
T\left(C_{0}\right) & =\left(\rho_{s} / \rho_{w}\right)\left(R_{o}^{2} / 2 D\left(C_{s}-C_{0}\right)\right) \\
& =r(0)\left[C_{s} /\left(C_{s}-C_{0}\right)\right] .
\end{aligned}
$$

This dependence on solution concentration explains the wide variation of particle dissolution times observed for sulfides in a crack tip. It shows that very long dissolution times could occur if a large inventory of sulfides has led to concentrations near $C_{s}$.

The diffusion equation must therefore be modified in cases where the dissolved sulfide concentrations are expected to be near the solubility limit. This occurs after exposure of a large inventory of fresh sulfides, e.g., due to breakthrough of an embedded defect. It also occurs in laboratory tests at startup due to air precracks or after extended periods of cycling at high rates. In these cases, the limited sulfide solubility will reduce dissolution rates of sulfides. The mathematics required in principle could be quite complicated, with the sulfide dissolution rate depending on the local concentrations. A modified version of Equation 5 which allows for dissolution rates reduced by solubility in Eqn. 10 is:

$$
\partial C / \partial t=D \partial^{2} C / \partial x^{2}+H k_{1}\left[\left(C_{s}-C\right) / C_{s}\right]
$$

The production of sulfides now depends on the local concentration $\mathrm{C}$, which in turn depends on position within the crack and time. This equation is valid only while all particles are dissolving at the local rate proportional to $k_{1}\left(C_{s}-C\right) / C_{s}$. It is valid only for times less than the particle dissolution times. In general, for times greater than the dissolution times of the first particles to dissolve, the local source strength becomes dependent on position and time i.e. $H=H(x, t)$. Solution of the fully general case becomes complicated and will be treated only after developing more simple, intuitive 
solutions with uniformly dissolving sources over the crack face.

The simplest case to treat is for steady state behavior $\mathrm{dC} / \mathrm{dt}=0$. Steady state is reached after transient times of order $a^{2} / D$, the diffusion response time for a crack of length a. For cracks of depth $10 \mathrm{~mm}$ of exposed sulfides, the diffusion transients for high solubilities would take only a few hours. In contrast, the sluggish sulfide dissolution observed in A302B leads to sulfide survival times of up to 300 hours in a crack with fresh sulfides of only $2.5 \mathrm{~mm}$ depth, so that the diffusion transients are not important in determining sulfide dissolution rates for large depths of undissolved sulfides. This allows use of the steady state equation, which is

$$
-d^{2} C / d x^{2}+\left(H k_{1} / D C_{s}\right) C=H k_{1} / D
$$

This is a linear, inhomogeneous equation of second order. The solution can be obtained as a sum of solutions for the homogeneous equation (right hand side of Equation $12=0$ ) and a particular solution of the inhomogeneous Equation 12 (Mathews and Walker, 1965). The solution for the homogeneous equation is $\exp ( \pm \mathrm{mx}$ ), where $m=\left(H k_{1} / D C_{s}\right)^{1 / 2}$. The sulfide source is in this case the dissolving sulfides on the crack flanks, so that the flux at the crack tip $x=0$ is zero, or $-D d C / d x=0$. The other requirement that $\mathrm{C}=0$ at the crack mouth $x=a$ leads to the final result

$$
C / C_{s}=[\cosh (m a)-\cosh (m x)] / \cosh (m a)(13 a)
$$

It is easily seen that for large solubility, $\mathrm{C}_{\mathrm{s}}$ very large, $\mathrm{ma}$ is very small, and the $\cosh (\mathrm{ma})$ is approximated by $1+(\mathrm{ma})^{2} / 2$, and using the definition of $\mathrm{m}$ above leads to

$\mathrm{C}=\mathrm{Hk}_{1}\left(\mathrm{a}^{2}-\mathrm{x}^{2}\right) / 2 \mathrm{D}$

independent of the solubility.

The maximum calculated value at the crack tip is

$$
C_{\max }=H k_{1} a^{2} / 2 D
$$

This reproduces the result obtained previously in Equation (7) which led to a very large sulfide level at short times.

The reduction of crack tip concentration for values of $\mathrm{C}_{3}<\mathrm{C}_{\max }$ is shown in Figure 4 .

Plots of the normalized concentration down the crack are shown in Figure 5 for a wide range of solubility ratios. For small solubility, or $\mathrm{C}_{\mathrm{s}} / \mathrm{C}_{\max }<.1$ the result is $\mathrm{C}=\mathrm{C}_{\mathrm{s}}$ over almost the whole crack. It is seen that for low solubility the slopes $\mathrm{dC} / \mathrm{dx}$ are low, showing reduced flux $F=-D d C / d x$ of sulfides with lower $\mathrm{C}_{\mathrm{s}}$. The reduced flux will delay sulfide dissolution.

\section{CONCENTRATION - TIME AND SPACE DEPENDENT SOURCES}

This section provides quantitative solutions for dissolution rates of sulfides in cracks. In order to calculate dissolution times for the array of sulfides in a real crack, time and space dependent sulfide concentration in the water must be considered. The metallurgical sulfide sources will also depend on position and time. A simple, physical approach yields an analytic result, verified by numerical calculations.

For the case of an embedded crack breaking through to the wetted surface, a uniform distribution of sulfides is exposed at time zero. The dissolution of sulfides will occur most rapidly near the crack mouth, $x=a$, where the concentration is lowest. In general, $\mathrm{H}$ will now become a function of the position $x$ and time. An analytic solution with time varying $H(x, t)$ would be complicated. It is shown that a simple physical calculation provides adequate results for a one dimensional crack, and is more illustrative of the physical process.

\subsection{Simplified Calculation}

A schematic of dissolution in a deep crack in the presence of limited solubility is shown in Figure 6. Dissolution of sulfides is assumed to quickly saturate the water over almost the whole crack and proceed at a low level. However, the interval nearest the crack mouth has a reduced concentration 
and a concentration gradient exists to drive diffusion so dissolution will proceed rapidly.

The remaining depth of undissolved sulfides is specified by $x_{3}(t)$, where $t$ is the time span for dissolution. The diffusion flux, $-\mathrm{DdC} / \mathrm{dx}$, is determined by the gradient in $\mathrm{C}$, which for deep cracks is given approximately by $\mathrm{C}_{s} /\left(\mathrm{a}-\mathrm{x}_{\mathrm{s}}(\mathrm{t})\right)$ sketched in Figure 6. The flux is equal to the production rate of dissolved sulfides, $H^{*} \mathrm{dx} / \mathrm{dt}$ leading to

$-D C_{3} /\left(a-x_{a}(t)\right)=H^{*} d x_{a} / d t,(m a>>1)$

valid for deep cracks

This equation can be integrated to yield the time dependent length of undissolved sulfides

$\left(a-x_{s}(t)\right)^{2}=2 D C_{s} t / H,(m a>>1)$.

The time $t_{\text {diss }}$ for dissolution of sulfides in a crack of depth is therefore

$t_{\text {dises }}(a) \approx \mathrm{Ha}^{2} / 20 \mathrm{C}_{8},(\mathrm{ma}>>1)$

The time for crack cleanup in a deep crack is independent of the dissolution constant for an isolated sulfide $k_{1}=1 / \tau$.

This means that the dissolution of a large sulfide array is limited by the solubility limit and diffusion only. The time to dissolve an array of sulfides of depth $a$ is quadratic in the depth of the array for either deep cracks or high sulfide densities such that ma $>1$.

\subsection{Exact Results}

In order to obtain exact, general results, a numerical analysis scheme was developed. The crack configuration is the same as before, but now the source of dissolving sulfides is considered to depend on time and position as shown in Figure 7. Sulfides are assumed to be dissolving between $x=0$ and $x=x_{s}$, and for $x>x_{s}$ the sulfides have been dissolved away.

The steady state concentration profile is similar to Equation (13a), but now depends on the position $x_{s}$ or remaining depth of dissolving sulfides $c / c_{8}=1-[\cosh (m x)] /\left[\cosh \left(m x_{8}\right)+\right.$

$\left.m\left(a-x_{3}\right) \sinh \left(m x_{s}\right)\right]$ for $x_{s} \geq x \geq 0$

and

$c / C_{s}=\left[m(a-x) \sinh \left(m x_{s}\right)\right] /\left[\cosh \left(m x_{s}\right)+\right.$

$\left.m\left(a-x_{s}\right) \sinh \left(m x_{3}\right)\right]$ for $a \geq x \geq x_{s}$

The dependence of concentration on $x_{s}$ is shown for several values of $\mathrm{ma}$ in Figure 8. The plots show the clear transition to linear behavior (constant flux) for $x \geq x_{8}$, and the decrease in $-d C / d x$ or diffusion flux as $x_{s}$ decreases.

$x_{3}$ is now a function of time, to be calculated by maintaining a record of the remaining sulfides in each interval $x$. For simplicity, the dissolved sulfide production rate in the ith interval is assumed to be given as $J_{1}=$ $\left.H k_{1}\left[C_{s}-C\left(x_{1}, t\right)\right) / C_{s}\right]$ until that interval is depleted, i.e., when $\Sigma J_{1}(\Delta t)=H$. After this, the production rate is zero in that interval. Figure 7 provides a schematic of the analysis.

Using the concentrations in Equation (17) and appropriate time increments, the position $x_{s}$ was calculated numerically. The time for sulfides being cleaned from the crack is the time at which $x_{s}(t)$ first decreases to zero. The results are shown in Figure 9, and it can be seen that the simplified analysis in Eqn. 16 is accurate within $10 \%$ or better for ma $>5$. A suitable description of $t_{\text {diss }}$ over the whole range was obtained as a best fit to the numerical results as given by Eqn. 18 .

$$
\begin{aligned}
t_{\text {diss }}(a) / r & =1.085+0.488(\mathrm{ma})^{2}, \mathrm{ma} \leq 9.5 \\
& \cong \frac{(\mathrm{ma})^{2}}{2}, \mathrm{ma} \geq 9.5 \quad(18 \mathrm{a})
\end{aligned}
$$

This can be conveniently expressed in terms of $\mathrm{C}_{\mathrm{s}}$ as in Eqn. 18b.

$$
\begin{aligned}
t_{\text {diss }}(a)= & 1.085 \tau+0.488 \mathrm{Ha}^{2} / D C_{s}, \\
& \left(\mathrm{Hk}_{1} \mathrm{a}^{2} / D C_{s}\right)^{1 / 2}<9.5 \\
= & \mathrm{Ha}^{2} / 2 \mathrm{DC} \mathrm{C}_{\mathrm{s}},\left(\mathrm{Hk}_{1} \mathrm{a}^{2} / \mathrm{DC}_{\mathrm{s}}\right)^{1 / 2}>9.5
\end{aligned}
$$

Because of its simplicity and accuracy Eqn. 18 can be used for dissolution estimates. 


\subsection{Effect of Crack Growth During Sulfide Dissolution}

The effect of additional crack growth on the concentrations and time to crack clean up can be assessed directly. The crack growth increment $\Delta a$ occurring during the cleanup is added to the initial embedded defect depth $a$ and the total sulfide depth $a_{4}=$ $\Delta a+a$ is used in Eqns. 17 or 18. In general, separate calculations based on the particular loading history and cycling frequency of interest would be performed to obtain $\Delta a$. The calculated crack extension will depend on whether EAC is on or off. As $C_{8}$ $>\mathrm{C}_{\mathrm{crth}}$, EAC is on at time zero for a large embedded defect and will remain on until almost all sulfides have dissolved. As the length $x_{s}$ of undissolved sulfides approaches zero for $t$ near $t_{\text {diss }}(a)$, however, the concentration of dissolved sulfides is reduced. Depending on cycling rates, EAC could turn off.

To assess this possibility, the diffusion flux $F$ is calculated for small $x_{3}$ from Eqn. 17 to be

$F=-D d C / d x=H k_{1} x_{s}, m x_{s}<<1$

Using this result, the rate of change of $x_{s}$ is then the difference between growth $\left(N_{\text {ead }}\right)$ and loss rate $\left(k_{1} x_{s}\right)$

$\dot{x}_{s}=V_{\text {eac }}-k_{1} x_{s}$

where $V_{\text {oxc }}$ is the average environmental crack growth rate with EAC on at the time $t_{0}$.

The steady state solution of Equation $19 \mathrm{~b}$ for $x_{s}$ is

$x_{s}=V_{e a c} / k_{1}$

For small values of $x_{s}$ the concentration at the crack tip from Eqn. 17a goes to

$C \cong C_{s} m^{2} a x_{s}=H k_{1} a x_{s} / D,\left(m x_{s}<1\right)$,

so that the steady state concentration of the growing crack becomes

$C=H V_{\text {eac }} a / D,\left(m x_{s} \ll 1\right)$
Since $E A C$ is on if $C \geq C_{c m}=H a V_{i n} / D$, from Eqn. 4, EAC will stay on if $V_{\text {eac }} \geq V_{\text {in }}$. Conversely, EAC will be turned off if

$V_{\text {eac }}<V_{\text {m }}$

for a relatively short period of time $\left(<1 / k_{1}\right)$ following the crack cleanup time $\mathrm{t}=\mathrm{Ha}_{\mathrm{t}}^{2} /\left(2 \mathrm{DC} \mathrm{C}_{\mathrm{s}}\right)$. This is just the additional time to clean the remaining small crack depth $V_{\text {eac }} / k_{1}$, and would be a few days at most.

Hence, $V_{\text {eac }}<V_{\text {in }}$ is required for EAC to be turned off, after most of the sulfides have been cleaned up by diffusion. It should be noted that this is only actually required for a few hours at the end of the soak period after dissolution of the sultides from the original embedded defect. Based on Eqn. 4 and 21 it is required that $V_{\text {eac }}<1.7 \mathrm{E}-7 \mathrm{~mm} / \mathrm{s}$ for a $7.5 \mathrm{~mm}$ embedded flaw, and $V_{\text {oec }}<$ $5 E-08 \mathrm{~mm} / \mathrm{s}$ for a $25 \mathrm{~mm}$ embedded flaw.

If $V_{\text {eac }}<V_{\text {in }}$ is ensured, the actual predicted crack growth during cleanup of a large embedded defect would be limited by

$V_{\text {oac }} t<V_{\text {ln }} t$
$=\left(D C_{\text {crit }} / \mathrm{Ha}\right)\left(\mathrm{Ha}^{2} / 2 D C_{s}\right)=a\left(C_{\text {crit }} / 2 C_{s}\right)$

using Equation (4) and Equation (18a). In cases where significant crack growth $\Delta a$ beyond the embedded defect size has occurred, the crack length a in Eqn. 22 must be increased to $a+\Delta a$. Providing $V_{\text {eac }}$ (the crack tip velocity with EAC on) is less than $V_{\text {in }}$ (the minimum velocity required to initiate EAC starting with a clean crack) for a short time after crack cleanup, the calculated additional crack extension due to EAC is a fraction of the embedded defect size. According to the model, there is little penalty in additional crack growth for an embedded defect breaking through in service as long as the crack tip velocity with EAC on is below the critical initiation velocity for a short time following crack cleanup.

As an example the EAC crack growth rates in $A 302 B$ are about 24 times the non EAC or corrosion fatigue crack growth rates at $243 C$ (James, 1994). It is seen that the limits on the corrosion fatigue velocity for embedded 
defects in high sulfur steel breaking through A302B are low; $2 E-8 \mathrm{~mm} / \mathrm{s}(.66 \mathrm{~mm} / \mathrm{yr})$ for a $2.5 \mathrm{~mm}$ flaw and 2E-9mm/s (0.066 mm/yr) for a $25 \mathrm{~mm}$ flaw. After a short quiet loading period EAC will be off, if crack growth rates under these velocities are attained. According to these sample calculations, the practical consequence of embedded defects is to reduce the allowable crack tip velocity to about $V_{\text {in }} / 24$. Hence, embedded defects can be treated the same way as surface cracks, except that the allowable crack tip velocity is about 24 times less. This reduction of 24 applies to the maximum EAC rate of 40 times the air rate, and more detailed descriptions of EAC with thresholds and upper slope region would provide a lesser reduction. Using the theoretical predicted dependence of $V_{\text {in }}$ on crack size and sulfide density, allowable values of crack growth rate can be assessed. Alternatively, if periods of quiet loading occur frequently, such that $V_{\text {eac }}<V_{\text {in }}$ for several days, EAC will be unstable, the only limit is then $V<V_{\text {in }}$ to prevent EAC initiation.

\section{COMPARISON WITH EXPERIMENT}

The time for dissolution of sulfides in an array depends on the material parameters $m=\left(H k_{1} / D C_{s}\right)^{1 / 2}$, and $k_{1}=1 / \tau$. Since the diffusion constant is known, the three unknown constants are $\mathrm{H}, \mathrm{C}_{3}$, and $\mathrm{k}_{1}$. These quantities must be obtained from experiment. The value for $\mathrm{H}$ for the high sulfur $A 302 B$ plate can be estimated from the initiation velocity tests and the relationship (Wire and $\mathrm{Li}, 1996$ )

$$
\mathrm{V}_{\mathrm{ln}}=\mathrm{DC} \mathrm{C}_{\mathrm{crit}} / \mathrm{Ha}
$$

Using $V_{\text {tn }}=5 E-07 \mathrm{~mm} / \mathrm{s}$, the minimum velocity observed for $\mathrm{A} 302 \mathrm{~B}$ for a crack length of $2.5 \mathrm{~mm}$ leads to a maximum estimate $\mathrm{H}=4.7 \mathrm{E}-02$. The constant $r$ applies to dissolution times in dilute solutions, and was observed to be roughly one to eight hours by Kuniya, et al. (1992).

For $\mathrm{A} 302 \mathrm{~B}$, it was found that a soak time of about two weeks was required to clean out sulfides in a crack of depth $2.5 \mathrm{~mm}$. Hence, this time was much greater than $T$, and Equation (16) can be used to estimate $C_{s}$.
Using a time of 12 days for dissolution and $H=4.7 E-02$ leads to an estimated value of $C_{s}$ of $7 \mathrm{ppm}$. This is in reasonable range of the solubilities observed by Combrade, et al. and III, et al. and is sensibly greater than the value of $C_{c t h}=3 \mathrm{ppm}$, the minimum value to activate EAC. Using the value $\mathrm{C}_{\mathrm{s}}=7 \mathrm{ppm}$ and $H$ for $A 302 B$ of $H=4.7 E-02$ leads to $m=\left(H k_{1} / D C_{2}\right)^{1 / 2}=3.4 / \mathrm{mm}$. It can be seen that the estimated parameter is self consistent, as for a $2.5 \mathrm{~mm}$ crack in A302B, the projected dissolution time would be $36 \tau$. Since $\tau$ is about 8 hours, then the projected time for dissolution of sulfides is about $\mathbf{3 0 0}$ hours, in the range of the observed times of 2 weeks to clean cracks in A302B.

The calculated values of the time for sulfide dissolution are compared with experimental times for EAC cessation in Figure 11. These tests were performed with a large, constant dwell time of 40 or 60 minutes between cycles to simulate realistic loadings ( $\mathrm{Li}$, 1997). EAC ceased in every case after a sufficient cycling period. It can be seen that the observed times for the cessation of EAC, lie about a factor of 2-6 below the theoretical curve with $H=0.047$. This is very reasonable, as this is a maximum value of $H$ estimated from the minimum value of $V_{1 n}$ observed from EAC initiation testing. The observed values for cessation times are closer on average to the line developed for $H=0.01$. Based on Eqn. 8 and the observed average area fraction of 0.0012 , the value of $H=0.01$ corresponds to $d_{\text {eff }} / d=4.2$. This is consistent with the value of $d_{\text {efi }} / d=5.2$ found by Wire and $\mathrm{Li}$ (1996) when the typical initiation velocity was used, as opposed to the minimum velocity for EAC initiation. Hence, it can be concluded that the tests by $\mathrm{Li}$ are reasonably well described by this theory.

The decreasing frequency test series by James (Figure 1) on the same high sulfur plate (1994) led to the concern for EAC cessation. EAC apparently stayed on during the final 1000 hours of the test, when the cycling occurred at a rate of $0.0001 \mathrm{~Hz}$. There was some evidence that the EAC rates were decreasing with time. The test involved fast cycling at the outset, with cycling occurring at a rate of up to $1 \mathrm{~Hz}$. In 
contrast, the EAC cessation tests by $\mathrm{L}$ began with a one hour dwell time between cycles. The total time of the test is far below the maximum curve for $\mathrm{H}=0.047$ in Figure 11 and the nominal $H=0.010$, implying that EAC would have ceased if testing were continued to longer times.

Data from a variable dwell time test which was a predecessor to the ones described above are also shown in Figure 11 (Li, 1997). This test was performed in the same water chemistry, temperature, and the same high sulfur plate material as the tests by $\mathrm{Li}$. However, the test involved a different load history, with cycling starting with zero dwell times and increasing to maximum of 1 hour. Further, the test was not run to the point that EAC completely turned off. The available data is bounded by the value $H=0.047$. The value of the da/dN decreased during the last phase of the test, suggesting that EAC shut off might be imminent. However, the total time of 2500 hours for this test is about three times that for tests with no fast cycling, suggesting that fast cycling has increased the duration of EAC.

From Equation 22, the crack extensions are limited to a fraction $\left(\mathrm{C}_{\mathrm{crt}} / 2 \mathrm{C}_{\mathrm{s}}\right)$ of the embedded defect size. The crack extensions during EAC from each of the tests by $L i$ are plotted in Figure 12 . It can be seen that the extensions are consistent with the limit expressed in Eqn. 22 of $\Delta \mathrm{a} / \mathrm{a}$ less than about 0.2 obtained for $\mathrm{C}_{\mathrm{s}}=7 \mathrm{ppm}$, $\mathrm{C}_{\mathrm{crtt}}=3 \mathrm{ppm}$. The observed value is more like $\Delta a / a=.06$. The actual ratio obtained is expected to be less than the maximum bounding condition in Eqn. 22, with $V_{\text {eac }}=$ $V_{\text {in }}$ as an upper limit.

The effects of the austenitic cladding in this model are simply to extend the diffusion path by the clad thickness $a_{c}$. The time for clean up of a defect of total length $a$ is now

$t=H\left(a^{2}-a_{c}^{2}\right) / 2 D C_{s}$

where $a$ is the total defect depth, and $a_{c}$ is the clad thickness

Equation 23 shows that for defects just penetrating the cladding, dissolution times would be very small. For $a_{c}=a / 2$, the time for dissolution rises to $3 / 4$ the value for a total defect size in a high sulfur, low alloy steel. Hence, for large crack depths, testing with defects of a given depth in high sulfur steel without cladding should give conservative estimates of dissolution times for the equivalent total defect depth including clad and base metal. The datum in Figure 12 for a clad specimen (Li, 1997) shows less than a third of the crack growth of the unclad companion. Hence, since the clad was about $50 \%$ of the crack depth, the effects were consistent with but larger than predicted from Eqn. 23. This suggests that Eqn. 23 is conservative.

The extensive testing performed by VanDerSluys and Emanuelson (1993), provides an opportunity to test this theory at 288C. In that test series, considerable testing was done to measure the conditions for EAC to turn off, by reducing the applied frequency at constant $\Delta \mathrm{K}$. For one of the materials tested, a A533B $0.013 \% S$ plate steel, sufficient numbers of cessation tests were performed in a low oxygen PWR environment to compare to this theory. In each test series, EAC was turned on at high frequencies, crack growth rates were measured at this frequency, and then the frequency was lowered. The process was repeated until EAC turned off. By summing the total time during the tests with EAC on and the total crack depth with exposed sulfides, crack depth versus time data were developed. In each test, EAC started at an initial crack length $a_{i}$ and ended at $a_{f}$, which was considerably larger than $a_{i}$. The quantity $\sqrt{ }\left(a_{1}^{2}-a_{1}^{2}\right)$ was plotted instead of the crack depth $a$, to account for the large crack extension.

A plot for EAC cessation shown in Figure 13 was constructed. The data from tests at 243C are included for comparison. The data show strong dependence on the crack depth as predicted by the theory. This is a very important result, because it shows that the underlying basis for the significant times for crack cleaning to occur are the same for the two different test series and temperatures. Further, the times at equivalent crack depth parameters are about a factor of forty smaller than those at $243 C$. 
Since these are different materials, and different test histories were used, this difference cannot be directly interpreted as a measure of temperature dependence. Fortunately, EAC initiation velocities were also obtained on this material by VanDerSluys (1993), as noted by Wire and $\mathrm{LI}$ (1996). As done for A302B, the quantity $V_{\text {in }}$ and crack depth can be used to estimate the effective sulfide density $H$. Using the value $V_{\text {in }}$ of $1.4 E-06 \mathrm{~mm} / \mathrm{s}$ for a crack depth of $43 \mathrm{~mm}, H=1.4 E-03$ was obtained. Since the area fraction for this material is 0.0007 (Wire and James, 1996), this is in fact close to the minimum estimated value of $\mathrm{H}$ from Eqn. 8. It is seen from Figure 13 that the times to EAC cessation are less by a factor of about 6 than calculated using the value $\mathrm{H}=1.4 \mathrm{E}-03$ and the value of $\mathrm{C}_{s}$ obtained from 243C. This may be evidence for increased solubility at the higher temperatures, consistent with the notion that solubility of sulfides will increase with increasing temperature.

Increasing sulfide solubility with higher temperature offers a plausible explanation for the fact that EAC was more persistent at $243 C$ than at $288 C$. This suggests that EAC may be less prevalent above $288 \mathrm{C}$, consistent with temperature study by James (1994). In that study, the crack growth rates in both the high sulfur plate and forging were very high at $288 \mathrm{C}$, but dropped to low corrosion fatigue levels at $316 \mathrm{C}$ and $343 \mathrm{C}$. Conversely, this would suggest that as temperature is decreased, sulfide solubility would decrease, first to values near and finally below $C_{\text {crit. }}$. Below $C_{\text {crt }}$ EAC would not be expected, assuming a critical sulfide level is required at lower temperatures for EAC. In fact, the maximum extent of EAC is reduced as temperature is decreased from $243 \mathrm{C}$ to $149 \mathrm{C}$ from 40 to a multiple of 5 times the air rate (James, 1994).

The original data by James (1994) in Figure 1 was reviewed in light of the theory developed. From Figure 1 , it is seen that the environmental crack tip velocity was much higher than $V_{i n}$ for a small $2.5 \mathrm{~mm}$ crack, $5 E-07 \mathrm{~mm} / \mathrm{s}$, except during final phase of the test. Hence, EAC would be driven to stay on in all but the final phase and the sulfide inventory would continue building up. A plot of the actual crack growth in the final two phases is shown in Figure 14. Using the last portion of the test only, the actual rate had dropped by a factor of 4.3 to a rate of $4.1 \mathrm{E}-08 \mathrm{~mm} / \mathrm{s}$, suggesting EAC was probably in the process of turning off during the final portion of the test. However, the crack was approximately 25 $\mathrm{mm}$ deep, so that the value of $V_{\text {in }}$ for this would be $5 E-08 \mathrm{~mm} / \mathrm{s}$. Hence, the crack growth rate barely met the condition $V_{\text {eac }}<V_{\text {in }}$ during this last portion, which lasted a total of about 1000 hours. By definition, EAC remained on, as the ratio of the environmental rate to the air rate was approximately 10 , as can be seen in Figure 1. This is an interesting result, as it shows that EAC rates can indeed be less than the maximum of $\mathbf{4 0}$ times the air rate for long periods of time. This demonstrates the conservatism in the use of the maximum rate for the condition $V_{\text {eac }}<V_{\text {in }}$. The hold time test with fast cycling also followed this pattern ( $L$, 1997), with an environmental ratio of about 10 for the last 1000 hour portion of the test.

A detailed characterization of sulfide morphology and distributions in high and medium sulfur steels was performed. Early results were published by James and Poskie (1993) and final results were published by Wire and James (1996). A partial set of the results is shown in Table 2 . The results were obtained by automated particle counting and sizing methods using SEM techniques. Multiple scans for a given specimen were performed, allowing estimates of variability for sulfide size, area fraction, etc.

Forgings of $0.008-0.011 \% \mathrm{~S}$ have area fractions about 4-6 times smaller than the high sulfur $A 302 B$ tested. Hence, the projected time for cleanup of a typical precrack would be reduced. If the dissolution time goes as particle size squared as calculated above in Eqn. 10, the value of $\tau$ for forgings would be reduced by the ratio $\left(R_{\text {forging }} / R_{\text {plate }}\right)^{2}$. The large sized particles will dominate the response, having the longest dissolution times and largest volumes, so the mean of the maximum 
sulfide dimension should be used. From typical measured results for plate and forgings, the mean for maximum diameter for the A302B plate is 14 microns while the mean maximum particle diameter varies from 2-7 microns in medium-sulfur forgings. Hence, the estimated dissolution time constant $\tau$ for the forgings would be four to fifty times less or a maximum of 2 hours, based on 8 hours used for plate.

The parameter $m$ for forgings is at most $1 / 2$ that for high sulfur $\mathrm{A} 302 \mathrm{~B}$, so from Eqn. 18a the crack cleanup time would be reduced by 16 to 200 times from that in high sulfur plate. Hence, the $2.5 \mathrm{~mm}$ cracks should clean up in only $2-20$ hours which is consistent with the observation that EAC has not been observed in compact tension specimens of forgings at 243-260C upon test startup as reported by Auten (1997) and James (1994). Further, EAC was not observed by James, et al. (1997) in such a forging with a deep (17mm) initial surface crack. The sulfides are apparently soaked away during heatup and standby delays prior to cycling. The measured critical velocity $V_{\text {in }}$ is 10 times higher for the forgings (Wire and $\mathrm{Li}, 1996$ ) so that $H$ was taken as 10 times lower than that for A302B. The line for $H=0.001$ is projected for such forgings in Figure 11 showing that EAC would not be expected to persist very long in such a material. For example, a typical precrack of $5 \mathrm{~mm}$ would clear up in a day.

\section{RESTRICTIONS ON APPLICABILITY OF THE MODEL}

The theory and consequences predicted are based on diffusion of sulfide ions in water as the rate limiting mass transport mechanism. This has been established for cracks in low oxygen, quasi-stagnant water by Combrade, et al. (1988). Further, the sulfide solubility was treated as a constant and diffusion transients were ignored as they are small for long times of interest for response times in applications. Under conditions of low sulfide solubility with diffusion being the dominant mass transport, the dissolution time of sulfides increases quadratically with crack depth. These predictions will not apply for widely differing conditions. For very deep cracks, the metallurgical sulfides may eventually be covered by oxides after long times leading to reduced dissolved sulfide levels and earlier cessation of EAC.

There are four mass transport processes through which sulfide ions may be removed from the crack-tip region: 1) diffusion due to a concentration gradient, 2) ion migration due to an electrochemical corrosion potential gradient, 3) fatigue "pumping" due to cyclic motion of the crack flanks, and 4) convective flow induced within the crack enclave due to external free stream flow. The times for dissolution of sulfides will be drastically shortened if high water flow is present, and mass transport is dominated by convection in the crack. Tests performed by James, et al. (1996) show that water flow of $5 \mathrm{~m} / \mathrm{s}$ can stop EAC in cracks of $14 \mathrm{~mm}$ depth with no detectable further EAC crack growth.

Crack pumping is considered very small for the low frequency loading of most interest for large components. However, the very long times predicted for deep crack cleanup by diffusion in stagnant water would be reduced by pumping of any degree. Qualitatively, it is clear that high frequency or loading conditions which predominantly cause crack closure would lead to dominance of crack pumping. Turnbull, et al. (1983) developed a quantitative description of crack pumping fluxes. Based on work by Turnbull, the flux due to pumping for $\mathrm{K}_{\min }=0.5 \mathrm{~K}_{\max }$ at a distance $\mathrm{x}$ from the crack tip can be approximated by

$$
F_{\text {pump }}=C(2 n t x)
$$

where $C$ is the average concentration of diffusing species, and $f$ is the loading frequency. This may be compared with the flux due to diffusion from an embedded defect (Eqn. 19a) which is for small $x_{s}$

$$
F_{\text {diff }}=D m^{2} x_{s} C_{s}=H k_{1} x_{s}
$$

Diffusion will still be important if $F_{\text {diff }}{ }^{*} T>F_{\text {pump }} / f$ where $T$ is the average dwell time between transients. $1 / f$ is the active pumping time of the actual transient. For $H=0.01$, and $k_{1}=0.1 / \mathrm{hr}$ this leads to 


$$
\mathrm{T}>\left(2 \pi \mathrm{C}_{\mathrm{g}}\right) / \mathrm{Hk}_{1}=0.04 \mathrm{hr}
$$

This rough estimate suggests that diffusion will be dominant for many cases where cycling occurs less frequently that once every several minutes. Certainly, pumping was negligible during the tests which cycled once per hour.

Ion migration effects would reduce sulfide ion mass transport and extend times for crack cleanup. Recent experiments by Andresen and Young (1995) directly demonstrate that the sulfide concentration at the crack tip is increased by the addition of oxygen to the water. The potential gradient induced by the oxygen concentrates the sultide ions at the crack tip. The mass transport is reduced below that projected by diffusion alone by this potential gradient. EAC appeared to stay on indefinitely in the VanDerSluys tests in oxygenated water at $204^{\circ} \mathrm{C}$. In that case, it is clear that greater ion migration effects would be expected, and the diffusion model would not directly apply.

Psaila-Dombrowski (1990) showed that in theory that ion migration can be history dependent even in low oxygen water. Following exposure to sulfates, predicted corrosion rates increased, leading to local, net electrochemical polarization, trapping sulfide ions at the crack tip. The analysis showed that polarization could lead to a second steady state condition with high sulfide ion concentrations at the crack tip and high corrosion rates. By analogy, it is speculated that the fast cycling portions of the tests on high sulfur $A 302 B$ by James (1994) at 243C may have polarized the crack to some degree and sustained EAC longer than the tests with no fast cycling. The extensive test series by VanDerSluys with fast cycling shows EAC staying on at $288^{\circ} \mathrm{C}$ only about 400 hours, consistent with greater sulfide solubility at higher temperatures.

\section{SUMMARY}

Life assessment analyses consider the breakthrough of a large, embedded defect which would expose sufficient sulfides to turn on EAC. The analysis above provides a basis for calculation of crack growth for embedded defects. Crack growth would be very high if EAC persisted, as was suggested by some accelerated laboratory tests. Tests under more realistic, slow cycling conditions have resolved this concern, by showing that EAC ceased after times which depended on the initial crack depth of exposed sulfides. However, the times for EAC persistence are much longer than may have been expected, based on the literature.

The literature indicates that diffusion is the dominant mass transport mode in quasistagnant low oxygen environments. At low crack tip velocities (low supply) diffusion should quickly restore the crack tip sulfide concentration to bulk solution ion concentrations. Given the relatively short times predicted for diffusion transients of 1-2 hours, and the sulfide dissolution time of 8 hours or less in open solution it would be expected that cracks would be cleaned within the longer observed sulfide dissolution times of $1-2$ days.

Diffusion analysis with limited sulfide solubility was able to explain the far longer times (>1000 hours) observed for persistence of EAC. The particle survival time depends on the difference between the saturation sulfide level $\mathrm{C}_{\mathrm{s}}$ and the concentration $C_{0}$ in solution, and is proportional to $\mathrm{R}_{0}^{2} /\left(\mathrm{C}_{\mathrm{s}}-\mathrm{C}_{0}\right)$. The survival time is now a function of the local sulfide concentration, and increases markedly for $C_{\text {o near }} \mathrm{C}_{\mathrm{s}}$. Many orders of magnitude variation in sulfide dissolution times have been frequently noted in the literature, and this model shows that sulfides can survive for long times in deep cracks which produce concentrations to $C_{s}$.

The diffusion analysis shows that EAC will turn off in an embedded defect if $V_{\text {eac }}$, the crack tip velocity with EAC on, is less than the initiation velocity $V_{\text {in }}$. This restricts the corrosion fatigue rate to about 24 times less than allowable in a clean surface crack. This condition is required for only a short time after the crack cleanup time $t_{\text {diss }}(a)$, the time for sulfides of crack depth a to dissolve. 
Despite the predicted long time for EAC duration in an embedded defect, the extent of crack extension with EAC will only be a small fraction of the embedded defect size. These theoretical predictions are consistent with experimental results in low oxygen environments. As a result, embedded defects will not lead to any significant additional crack growth, providing $V_{\text {eac }}<V_{\text {in }}$ can be met. Since this condition need only be met for a few days following $t_{\text {diss, }}$, it is likely that this crack tip velocity limit need not be invoked for any system which has periodic periods of quiet loading. For such systems the criterion for EAC initiation in clean surface cracks is appropriate.

To illustrate the impact of the limit $V_{\text {oac }}<V_{\text {in }}$, the EAC behavior of high sulfur $A 302 B$ at $243 C$ was used. $V_{\text {eac }}$ is about 24 times the non EAC crack growth rate, at $243 C$ (James, 1994) so for this case this theory indicates that the practical consequence of embedded defects is to reduce the allowable crack tip velocity to $V_{\text {in }} / 24$ for embedded defects with large sulfide inventories. For clean surface cracks, the crack velocity is limited to $V_{\text {in }}$. Hence, embedded defects can be treated the same way as surface cracks, except that the allowable crack tip velocity is now significantly reduced. Using the theoretical predicted dependence of $V_{\text {in }}$ on crack size and sulfide density, allowable values of crack growth rate can be assessed. Alternatively, if periods of quiet loading lasting several days occur frequently, the allowable velocity would be increased to $V_{\text {in }}$ for embedded defects.

\section{ACKNOWLEDGEMENT}

The author expresses his thanks to A. Madeyski for SEM examination of sulfide lifetime.

This work was performed under U.S. Department of Energy Contract DE-AC11. 93PN38195 by Westinghouse Electric Corporation.

\section{REFERENCES}

Andresen, P. L. and Young, L. M., 1995, "Crack Tip Microsampling and Growth Rate Measurements in Low-Alloy Steel in HighTemperature Water", Corrosion, Vol. 51, No. 3, pp. 223-233

Auten, T. A., and Monter, J. V., 1995, "Temperature and Environmentally Assisted Cracking in Low Alloy Steel", Proceedings of the Seventh International Symposium on Environmental Degradation of Materials in Nuclear Power Systems - Water Reactors, NACE, pp. 1145-1154

Carslaw, H. S. and Jaeger, J. C., 1959, Conduction of Heat in Solids, Second Edition, Oxford at the Clarendon Press, London, England, pp. 257

Combrade, P., Foucault, M. and Slama, G., 1988, "Effect on Sulfur on the Fatigue Crack Growth Rates of Pressure Vessel Steel Exposed to PWR Coolant: Preliminary Model for Prediction of the Transition Between High and Low Crack Growth Rates", Proceedings of the Third International Conference, Environmental Degradation of Materials in Nuclear Power Systems - Water Reactors. Edited by G. J. Theus and J.R. Weeks, the Metallurgical Society, pp. 269-276

Combrade, P., Foucalt, M., Marcus, P., and Slama, G., 1990 "On the Role of Sulfur on the Dissolution of Pressure Vessel Steels at the Tip of a Propagating Crack in PWR Environments", Proceedings of the Fourth International Conference on Environmental Degradation of Materials in Nuclear Power System-Water Reactors, Edited by D. Cubicciotti, NACE, pp 8-48

Cussler, E. L., 1984, Diffusion, Cambridge University Press, 40 West 20th Street, New York, NY 
IIIi, H., Chantreau, E. and Hanninen, H., 1987, Application of Miniature Autoclaves in the Study of Crevice Chemistry at High Temperatures", Corrosion Chemistry within Pits. Crevices and Cracks, Edited by A. Turnbull, Her Majesty's Stationery Office, London, pp. 271-286

James, L. A. and Poskie, T. J., 1993, "Correlations Between MnS Area Fraction and EAC Behavior, Technical Report WAPDT-3012, Available from the DOE Office of Scientific Technical Information, Oak Ridge, Tenn.

James, L. A., 1994, "The Effect of Temperature and Cyclic Frequency Upon Fatigue Crack Growth Behavior of Several Steels in an Elevated Temperature Aqueous Environment", Journal of Pressure Vessel Technology, Vol. 116, No. 2, pp. 122-127

James, L. A., 1995, "EnvironmentallyAssisted Cracking of Ferritic Steels in Aqueous Environments: An Interpretive Review", Welding Research Council Bulletin No. 404, pp. $1-20$

James, L. A., Wire, G. L., and Cullen, W. H., 1995, "The Effect of Water Flow Rate Upon the Environmentally-Assisted Cracking Response of a Low-Alloy Steel," Journal of Pressure Vessel Technology, Vol. 117, No. 3, pp. 238-244

James, L. A., Auten, T. A., Poskie, T. J., and Cullen, W. H., 1996, "Corrosion Fatigue Crack Growth in Clad Low-Alloy Steels: Part I, Medium-Sulfur Forging Steel", WAPD-T-3095, Available from the DOE Office of Scientific Technical Information, Oak Ridge, Tennessee, submitted to the Journal of Pressure Vessel Technology

Kuniya, J., Anzai, H., and Masoaoka, I., 1992 "Effect of MnS Inclusions on Stress Corrosion Cracking in Low-Alloy Steels", Corrosion, Vol. 48, No. 5, pp. 419-425
Li, Y. Y., 1997, "Cessation of Environmentally-Assisted Cracking in a LowAlloy Steel: Experimental Results", WAPD-T-3127, Available from the DOE Office of Scientific Technical Information, Oak Ridge, Tenn, to be presented at the 1997 ASME Pressure Vessel and Piping Conference, July 27-31, 1997, Orlando, Fla.

Mathews, J. and Walker, R. L., 1965, Mathematical Methods of Physics, W. A. Benjamin, Inc., pp. 6-9

Matsushima, S., Katada, Y., Sato, S. and Nagata, N., 1991, "Dissolution Behavior of MnS Inclusions In Low Alloy Steels In High Temperature Water", Seventh APCCC Conference, pp. 112-117

Psalia-Dombrowski, M. J., 1990 "Modeling of Crack and Crevice Chemistry in Light Water Reactor Environments", Doctoral Thesis at MIT

Pumphrey, P. H., 1980, "The Role of Sulfide Inclusions in Hydrogen Entry During the Exposure of Steels to Acids," Corrosion 36, No. 10 pp. $537-543,1980$

Scott, P. M., 1988, "A Review of Environmental Effects on Pressure Vessel Integrity", Proceedings of the Third International Conference, Environmental Degradation of Materials in Nuclear Power Systems-Water Reactors. Edited by G. J. Theus and J.R. Weeks, the Metallurgical Society, pp. 15-29

Shoji, T., Takahasi, H., Suzuki, M. and Kondo, T., 1981, "A New Parameter for Characterizing Corrosion Fatigue Crack Growth", ASME J. of Engineering Materials and Technology 103, pp. 298-304

Turnbull, A., 1983, "A Theoretical Evaluation of the Oxygen Concentration in a CorrosionFatigue Crack," Corrosion Fatigue: Mechanics, Metallurgy, Electrochemistry, and Engineering, ASTM STP 801, T. W. Crooker and B. N. Leis, Eds., American Society for Testing and Materials, pp. 351-366. 
VanDerSluys, W. A. and Emanuelson, R. H., 1988, "Enhancement of Fatigue Crack Growth Rates in Pressure Boundary Materials Due to Light-Water-Reactor Environments", Proceedings of the Third International conference on Environmental Degradation of Materials in Nuclear Power Systems - Water Reactors, Edited by G. J. Theus and J. R. Weeks, the Metallurgical Society, pp. 277-282

VanDerSluys, W. A. and Emanuelson, R. H., 1993, "Environment Acceleration of Fatigue Crack Growth in Reactor Pressure Vessel Materials", EPRI TR-102796, Vol. 1, Electric Power Research Institute, Palo Alto, CA.

Weast, R. C., 1983-84, CRC Handbook of Chemistry and Physics, 64th Edition, CRC Press, Inc., Boca Raton, Fla, p. B219

Wire, G. L. and Li, Y. Y., 1996, "Initiation of Environmentally-Assisted Cracking in LowAlloy Steels", 1996 ASME PVP \& ICPVT Pressure Vessels and Piping Conference, July 21-26, Montreal, Quebec, Canada, published in Fatique and Fracture - 1996, PVP-Vol. 323, pp. 269-289

Wire, G. L. and James, L. A., 1996, "Correlations Between MnS Area Fraction and EAC Behavior, Technical Report WAPDT-3106, Available from the DOE Office of Scientific Technical Information, Oak Ridge, Tenn.

Young, L. M. and Andresen, P. L., 1995 "Crack Tip Microsampling and Growth Rate Measurements in a $0.021 \%$ S Low Alloy Steel in High Temperature Water", Proceedings of the Seventh International Symposium on Environmental Degradation of Materials in Nuclear Power Systems - Water Reactors, NACE, pp. 1193-1202 
Table 2

Sulfide Distribution Measurements for Several Steels

\begin{tabular}{||c|c|c|c|c|c|}
\hline Steel & Heat & $\begin{array}{c}\text { Local Sulfur, } \\
\text { wt \% }\end{array}$ & $\begin{array}{c}\text { Sulfide } \\
\text { Area } \\
\text { Fraction }\end{array}$ & $\begin{array}{c}\text { Average } \\
\text { Sulfide } \\
\text { Diameter } \\
\mu \mathrm{m}\end{array}$ & $\begin{array}{c}\text { Mean } \\
\text { Maximum } \\
\text { Diameter } \\
\mu \mathrm{m}\end{array}$ \\
\hline A302B Plate & 21478 & 0.024 & $\begin{array}{c}0.0012 \\
\pm 0.0005\end{array}$ & 4.7 & 13.9 \\
\hline A508-2 Forging & 5610 & 0.011 & $\begin{array}{c}0.00034 \\
\pm 0.0001\end{array}$ & 3.1 & 7.3 \\
\hline A508-2 Forging & 53718 & 0.011 & $\begin{array}{c}0.00032 \\
\pm 0.0001\end{array}$ & 1.7 & 2.2 \\
\hline A508-2 Forging & Q-71-24 & 0.008 & $\begin{array}{c}0.00026 \\
\pm 0.0001\end{array}$ & 4.1 & 6.4 \\
\hline A508-4 Forging & $122 Z 195$ & 0.004 & $\begin{array}{c}0.0001 \\
\pm 0.00002\end{array}$ & 1.34 & 1.55 \\
\hline A508-4 Forging & SP2908 & 0.007 & $\begin{array}{c}0.00022 \\
\pm 0.00003\end{array}$ & 1.44 & 1.66 \\
\hline
\end{tabular}


Table 3

Sulfide Solubility at High Temperatures

\begin{tabular}{|c|c|c|c|c|c|}
\hline $\begin{array}{c}\text { Initial } \\
\text { Water } \\
\text { Chemistry }\end{array}$ & Additions & $\mathrm{pH} 25^{\circ} \mathrm{C}$ & Mn-ppm & Fe-ppm & $\begin{array}{l}\text { Sulfate- }^{+} \\
\text {ppm }\end{array}$ \\
\hline Pure (1) & $\begin{array}{c}\text { FeS } \\
\text { Saturated }\end{array}$ & -- & - & -- & 5 \\
\hline $\begin{array}{l}7500 \text { ppmB, } \\
\text { LiOH (1) }\end{array}$ & $\begin{array}{c}\text { FeS } \\
\text { Saturated }\end{array}$ & $\begin{array}{c}7 \\
\text { initial }\end{array}$ & - & - & $80-90$ \\
\hline $\begin{array}{l}7500 \text { ppmB, } \\
\text { LiOH (1) }\end{array}$ & $\begin{array}{c}\text { MnS } \\
\text { Saturated }\end{array}$ & $\begin{array}{c}7 \\
\text { initial }\end{array}$ & - & - & $40-50$ \\
\hline $\begin{array}{l}1000 \text { ppmB, } \\
\text { LiOH (1) }\end{array}$ & $\begin{array}{c}\text { FeS } \\
\text { Saturated }\end{array}$ & $\begin{array}{c}6.8 \\
\text { initial }\end{array}$ & -- & -. & $21-25$ \\
\hline $\begin{array}{l}1000 \text { ppmB, } \\
\text { LiOH (1) }\end{array}$ & $\begin{array}{c}\text { FeS } \\
\text { Saturated }\end{array}$ & $\begin{array}{c}7.5 \\
\text { initial }\end{array}$ & -- & -- & $50-66$ \\
\hline $\begin{array}{l}1000 \text { ppmB, } \\
\text { LiOH (1) }\end{array}$ & $\begin{array}{c}\text { Mns } \\
\text { Saturated }\end{array}$ & $\begin{array}{c}7.5 \\
\text { initial } \\
\end{array}$ & -- & -- & $6-10$ \\
\hline $\begin{array}{l}1000 \text { ppmB, } \\
2 \text { ppm LiOH (1) }\end{array}$ & $\begin{array}{c}\text { MnS } \\
\text { Saturated }\end{array}$ & $\begin{array}{c}=6 \\
\text { initial }\end{array}$ & -- & -- & $<1$ \\
\hline Deionized (2) & None & $\begin{array}{l}3.8 \\
\text { final }\end{array}$ & 1.7 & 1.9 & 0.57 \\
\hline Deionized (2) & $2.5 \mathrm{mg} \mathrm{MnS}$ & $\begin{array}{c}4.9 \\
\text { final }\end{array}$ & 30 & 1.3 & 2.49 \\
\hline Deionized (2) & $12.4 \mathrm{mg} \mathrm{MnS}$ & 4.9 & 81 & 2.8 & 5.2 \\
\hline
\end{tabular}

(1) Combrade, (1989) Exposed at $290 \mathrm{C}$ for 100 hours $B=$ Boric Acid

(2) H. Illi, et al. (1987) Exposed at $273 \mathrm{C}$ for 25 days Volume $=5 \mathrm{ml}$

$+\quad$ Sulfides formed at high temperature transform to sulfates at room temperature where measurements are made. 


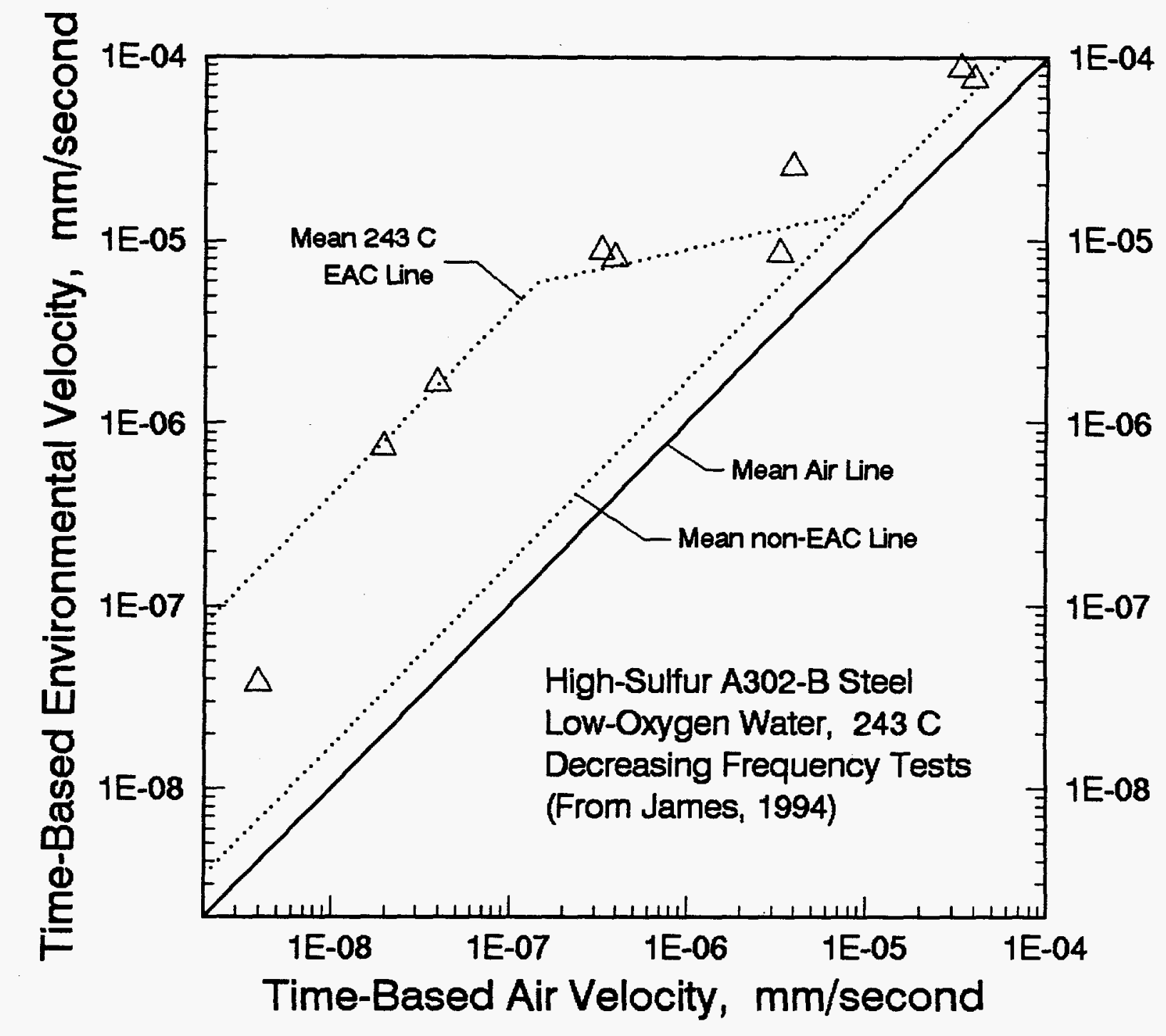

PVP97X.DRW

Figure 1. Persistence of EAC to Low Crack Velocities at $243 C$ in A302B High Sulfur Steel Plate (James 1994) 


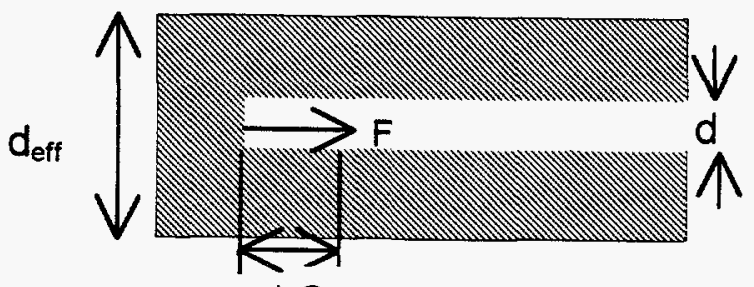

$\Delta \mathrm{a}$

Sulfides

exposed by

crack extension
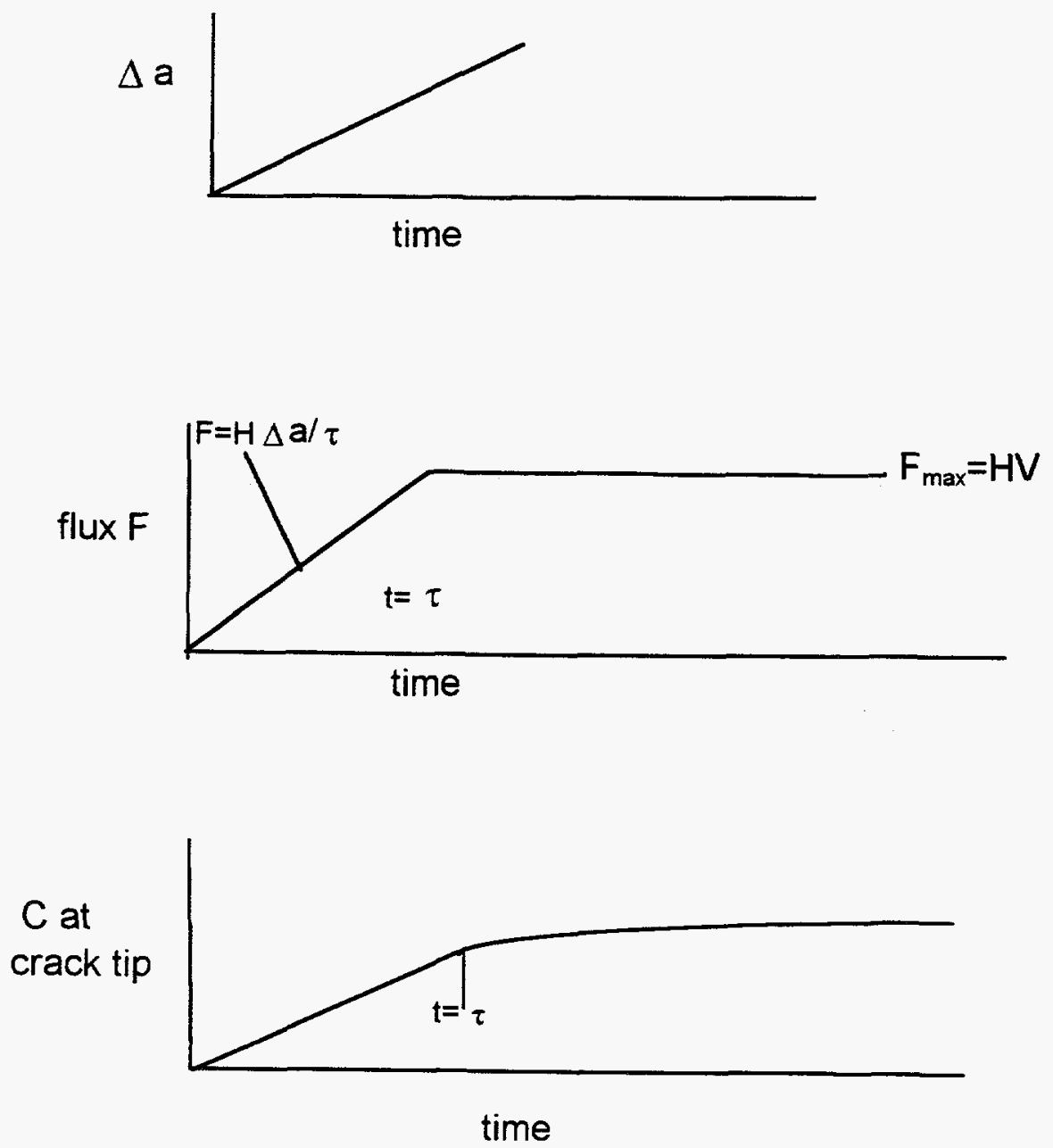

Figure 2. Schematic of Dissolved Sulfide Concentration for EAC Initiation

Crack extension at constant rate starting at $t=0$ exposes sulfides of length $\Delta \mathrm{a}=\mathrm{Vt}$. Slow dissolution with time constant $r$ leads to flux $F=H \Delta a / \tau$ which rises to a maximum of $H V$, and a maximum crack tip concentration $C=H V a / D$ 


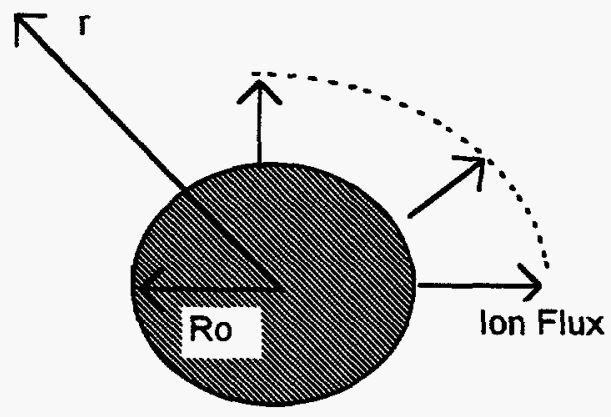

Particle of Radius $R_{\circ}$ Dissolving

If solution is very dilute, $\mathrm{C}=0$ at large $r$ so $C=C_{s} R_{d} / r$

Flux $j=D C_{s} / r=D C_{s} / R_{o}$ at surface

If the overall solution concentration is $C_{0}$ $j=D\left(C_{s}-C_{o}\right) / R_{o}$ at particle surface reduced by $\left(\mathrm{C}_{\mathrm{s}}-\mathrm{C}_{\mathrm{o}}\right) / \mathrm{C}_{\mathrm{s}}$

Figure 3. Sulfide Dissolving in Open Solution 


\section{CONCENTRATION DEPENDENCE ON $\mathrm{C}_{s}$}

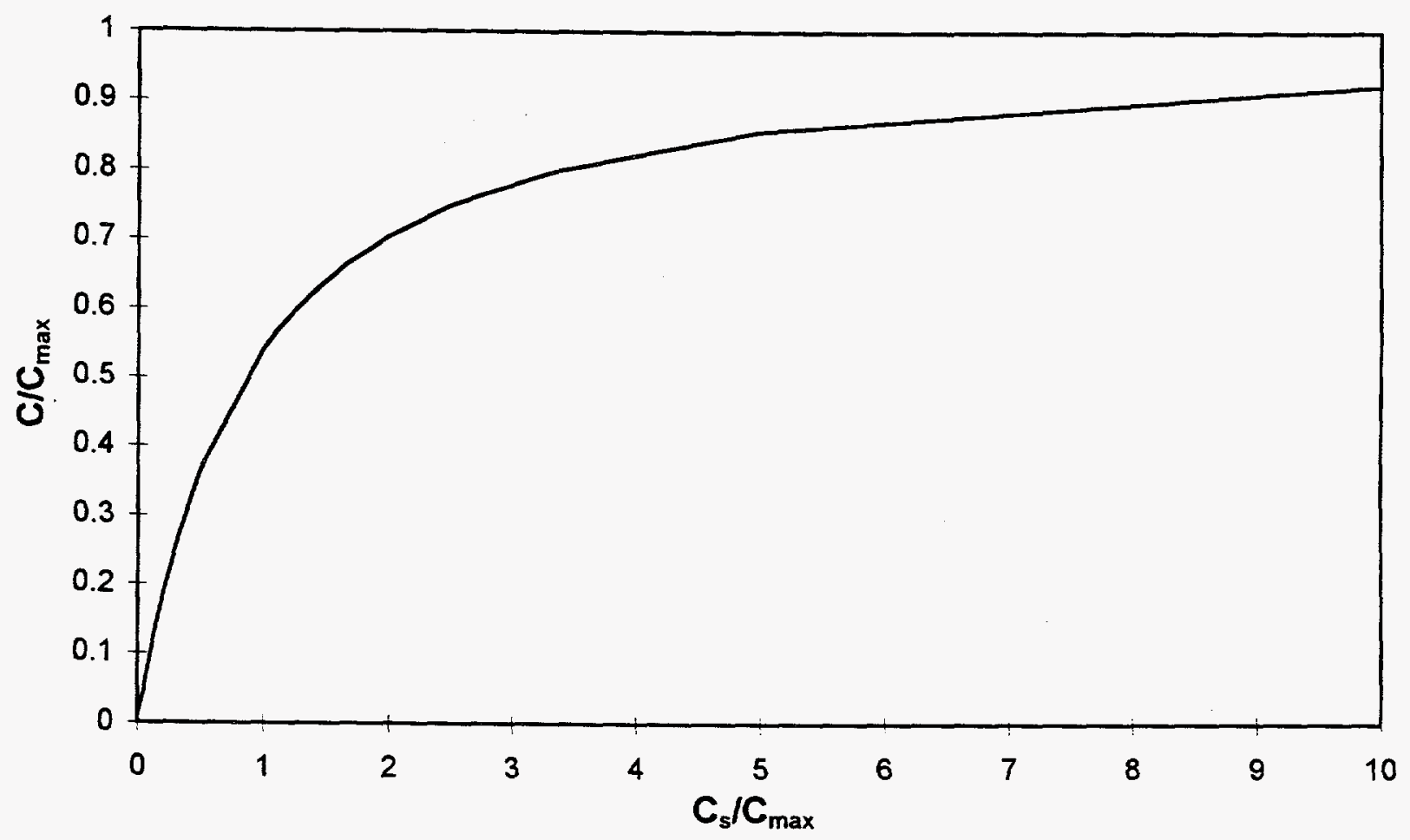

Figure 4. Concentration of Dissolved Sulfides in a Crack for Sulfide Dissolution Limited by Solubility

$\mathrm{C}_{\max }$ is crack tip concentration for unlimited solubility and $\mathrm{C}_{s}$ is the saturation concentration. 


\section{EFFECT OF SOLUBILITY ON CONCENTRATION}

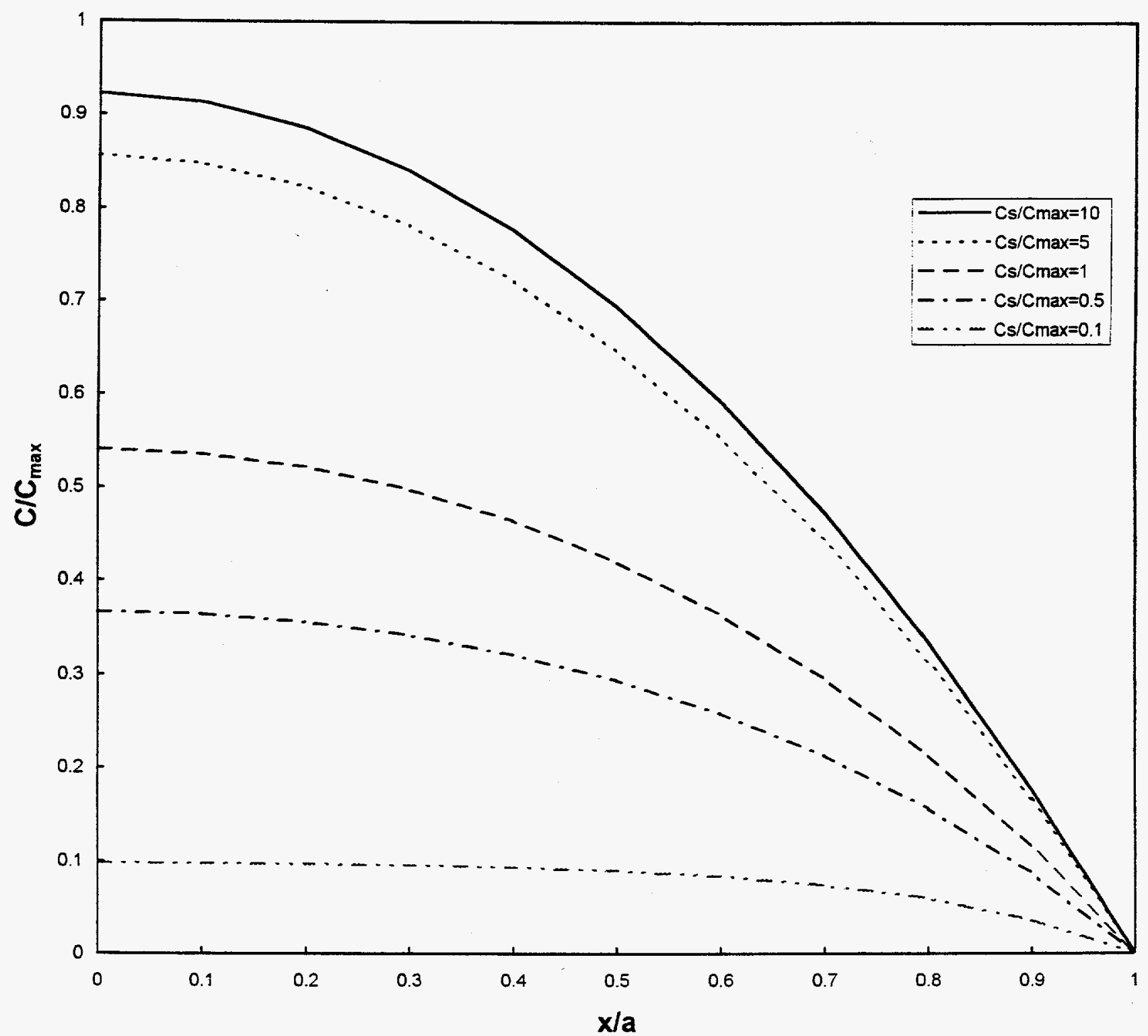

Figure 5. Normalized Concentration of Dissolved Sulfides in a Crack of Depth a As the solubility limit $C_{s} / C_{\max }$ decreases, the concentration goes to $C_{s}$ over most of the crack. 


\section{Crack With Exposed Sulfides}

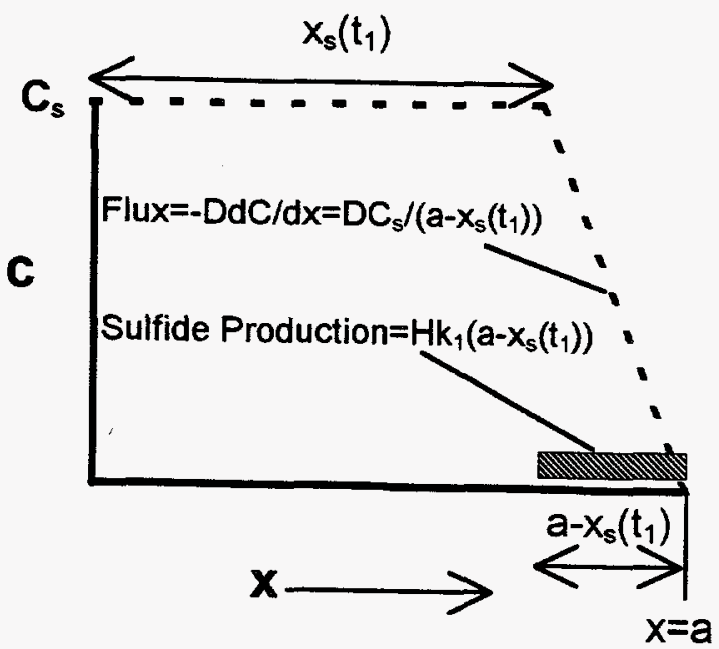

Time between 0 and $t_{1}$

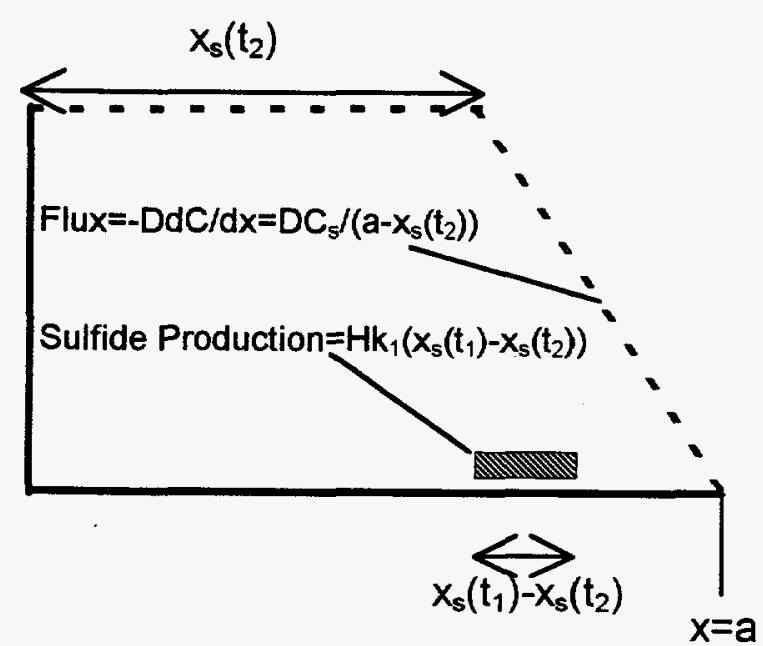

Time between $t_{1}$ and $t_{2}$

Figure 6. Schematic of Dissolution Occurring in Steps

Dissolution of sulfides exposed in a deep crack with limited solubility $C_{s}$ proceeds in stages starting at the crack mouth. 


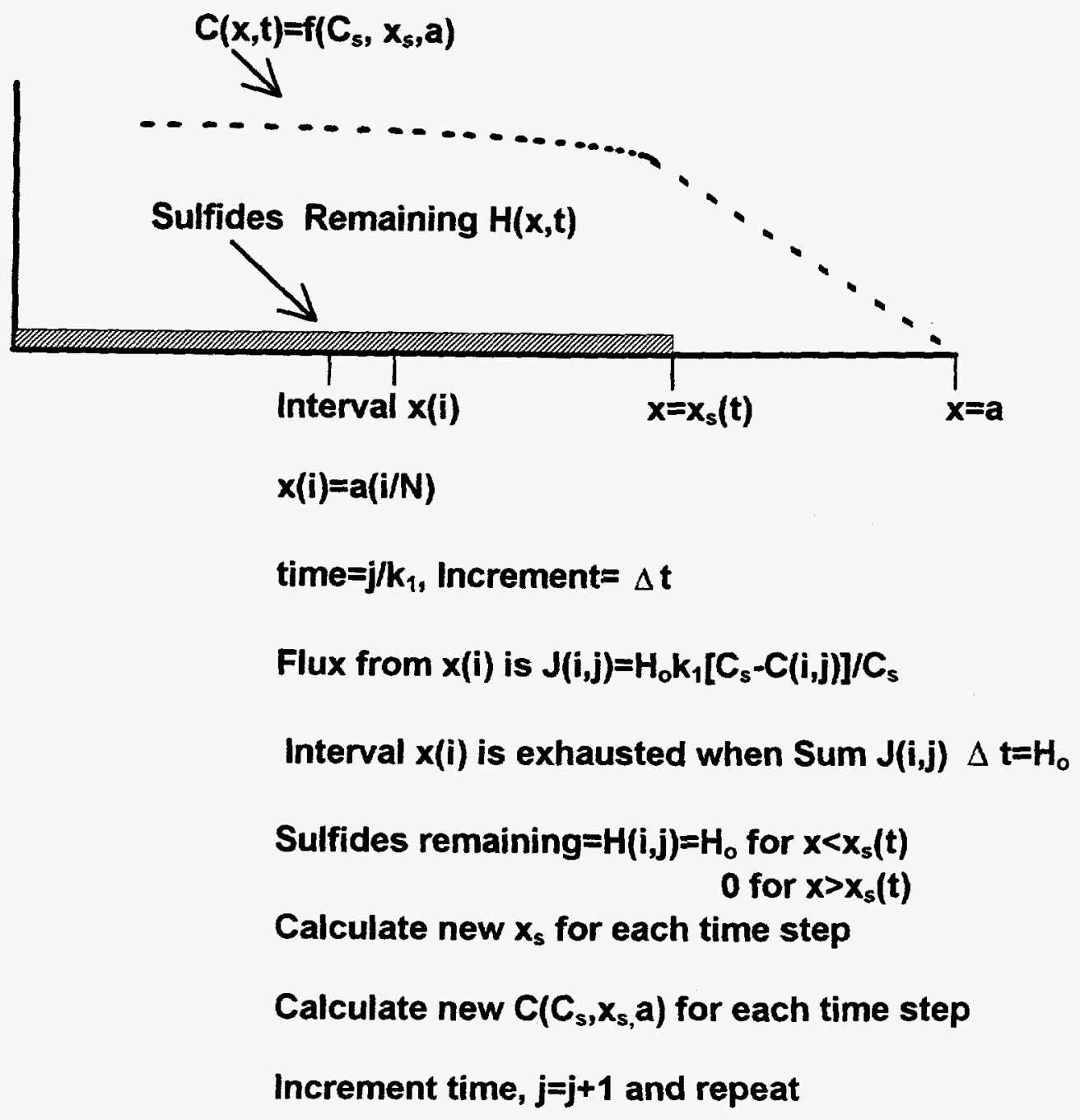

Figure 7. Model for Numerical Analysis of Sulfide Dissolution 


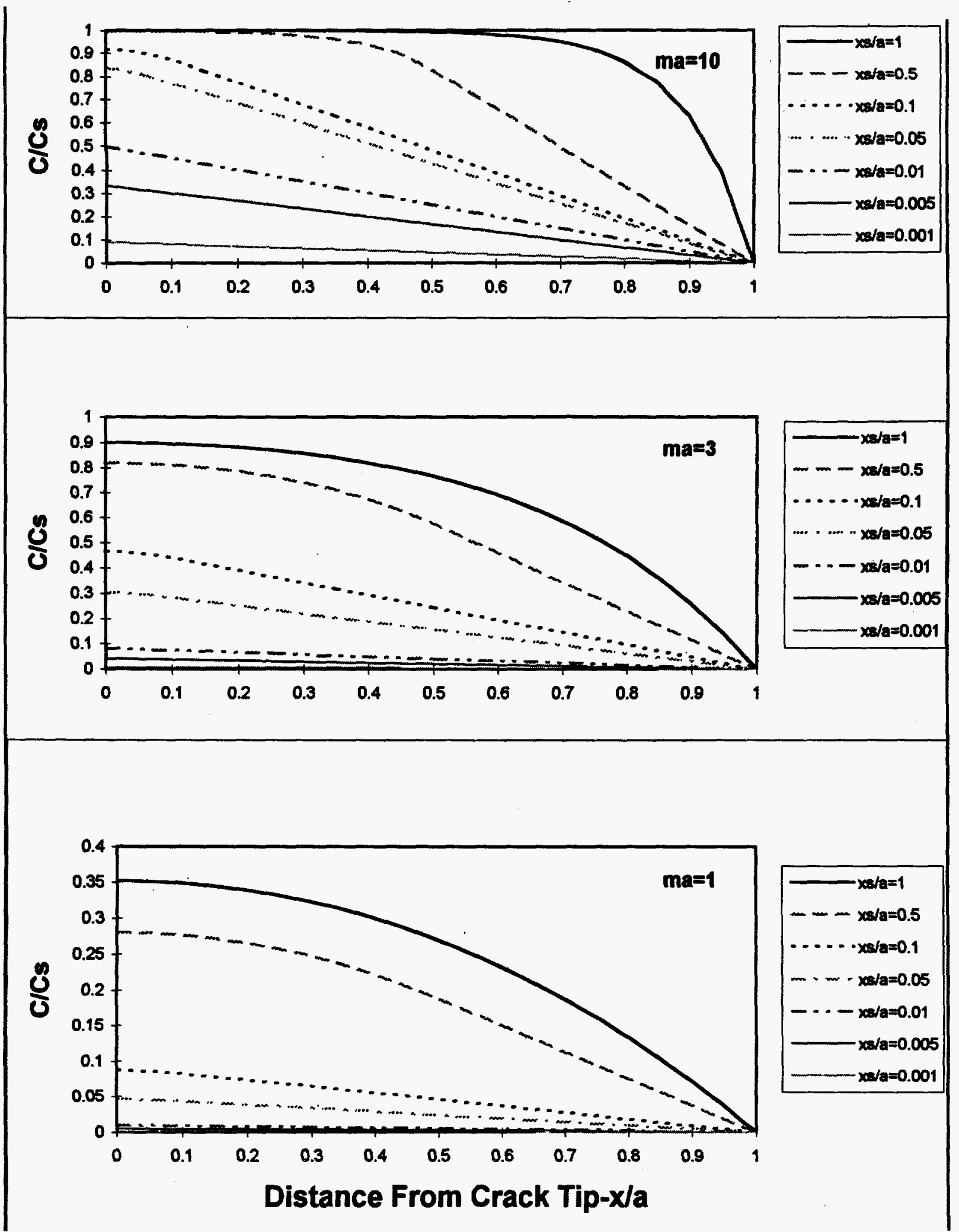

Figure 8. Concentration in a Crack with Sulfides Dissolved to $x_{s}$ from Crack Tip

$m a$ is a normalized defect depth, and $m a=10$ is a large defect for which $C=C_{s}$ at $x_{s}=1 . m a=1$ is a small defect, and $C$ is not limited by $C_{s}$. The concentration changes slowly for $x<x_{s}$, and goes to zero linearly for $x>x_{s}$. 


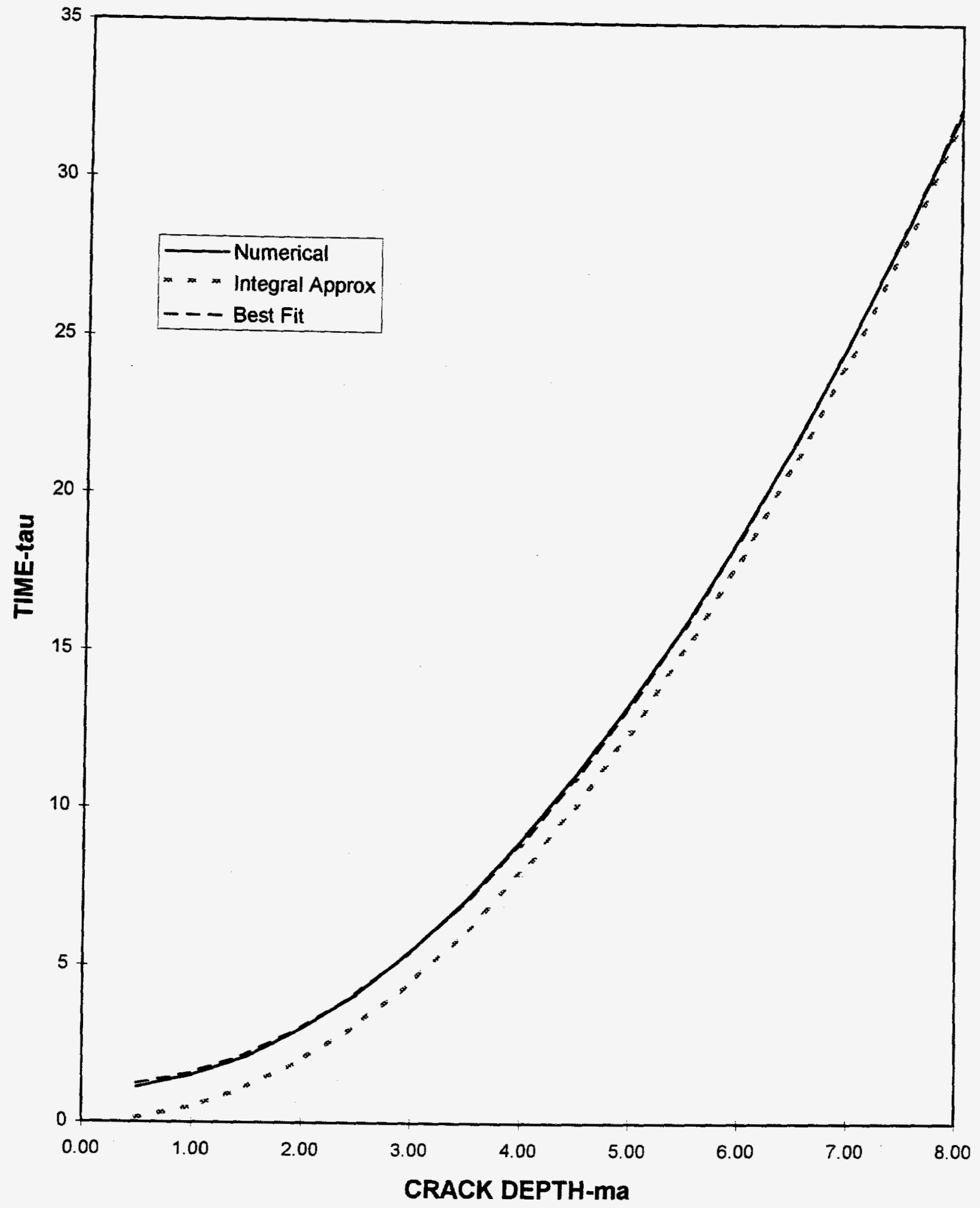

Figure 9. Calculated Dissolution Time $t_{\text {diss }} / \tau$ for Embedded Defect of Depth a

The "Best Fit" approximation is nearly indistinguishable from the exact calculations, and for large $m a, t_{\text {diss }} / \tau$ becomes equal to $(m a)^{\wedge} 2 / 2=\mathrm{Ha}^{\wedge} 2 /\left(2 D C_{s} \tau\right)$. 


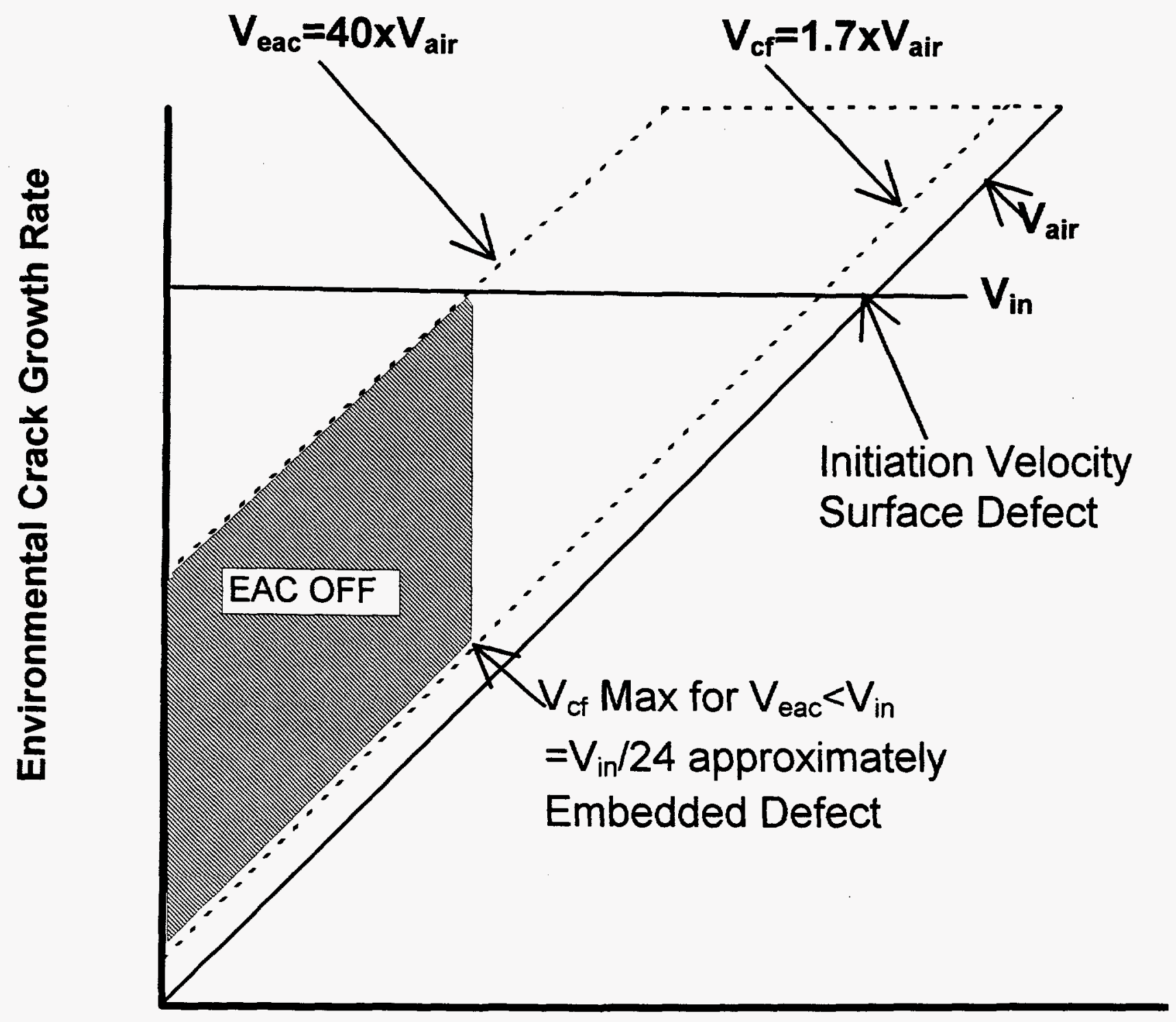

\section{Air Crack Growth Rate}

Figure 10. Example of Reduction of Allowable Velocity for Embedded Defects - Based on high sulfur A302B at 243C (James, 1994) 


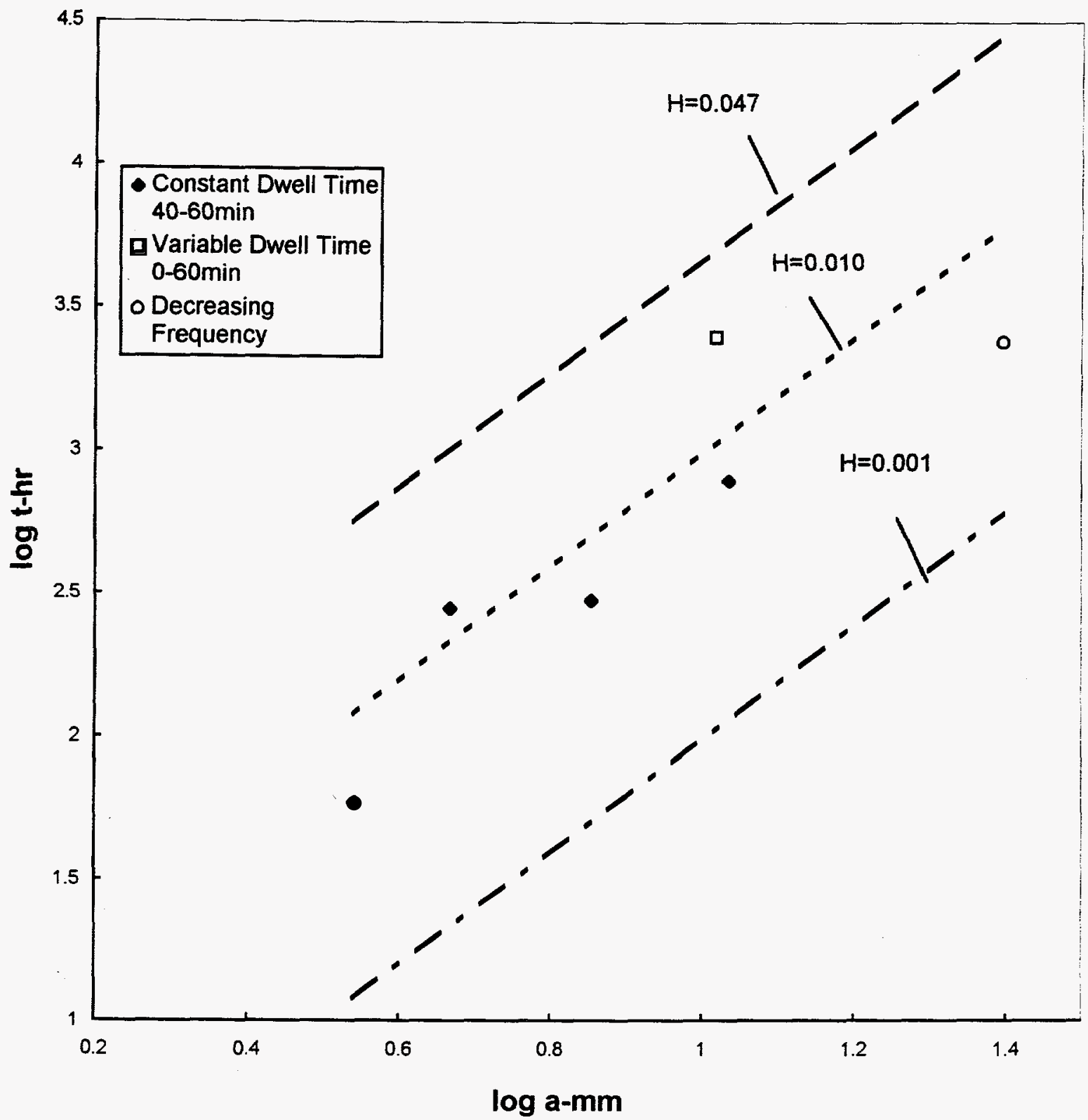

Figure 11. Calculated Dissolution Times and Experimental Results on High Sulfur A302B at 243C 


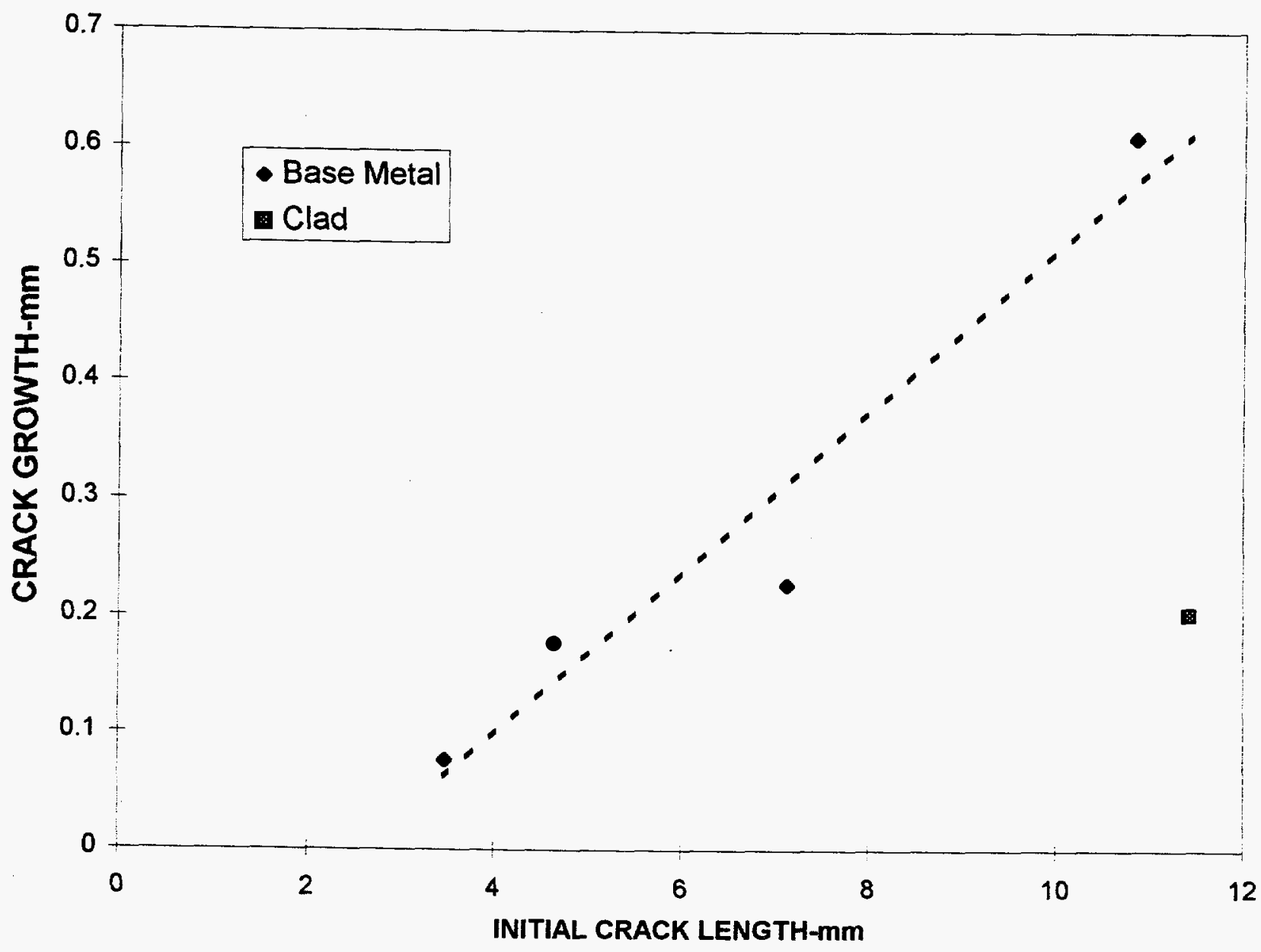

Figure 12. Crack Growth of Simulated Embedded Defects in High Sulfur $A 302 B$ at $243 C$

For the same total initial crack depth, the growth was less for the specimen with austenitic cladding. 


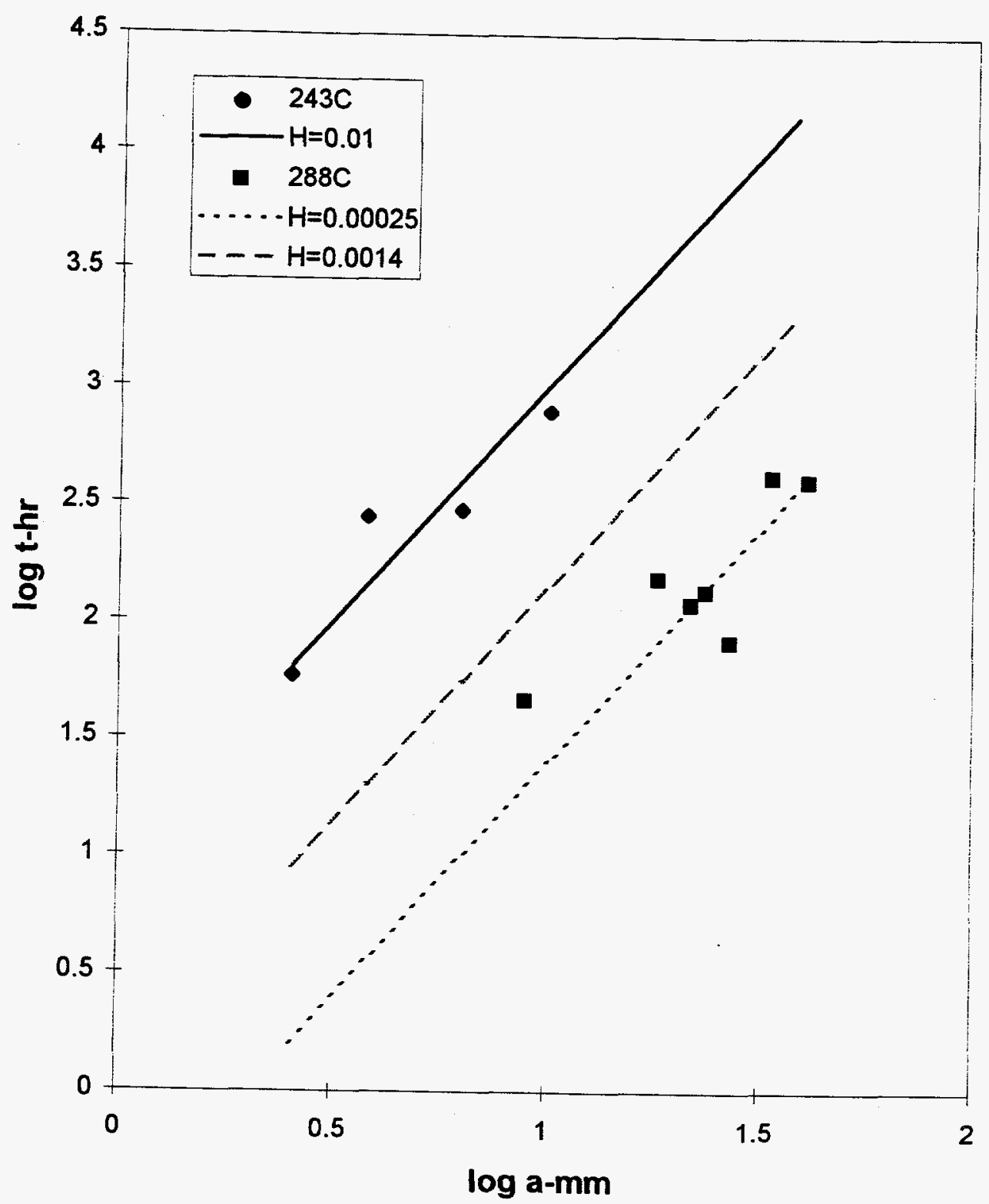

Figure 13. Comparison of EAC Cessation Tests on $A 302 B$ at $288 C$ $(0.024 \% S)$ and $A 533 B(.013 \% S)$ at $243 C$

The cessation times at $288 \mathrm{C}$ were 40 times lower than at $243 \mathrm{C}$ at similar crack depths and about six times lower than the minimum $\mathrm{H}=0.0014$, suggesting that $\mathrm{C}_{s}$ decreases with increasing temperature. 


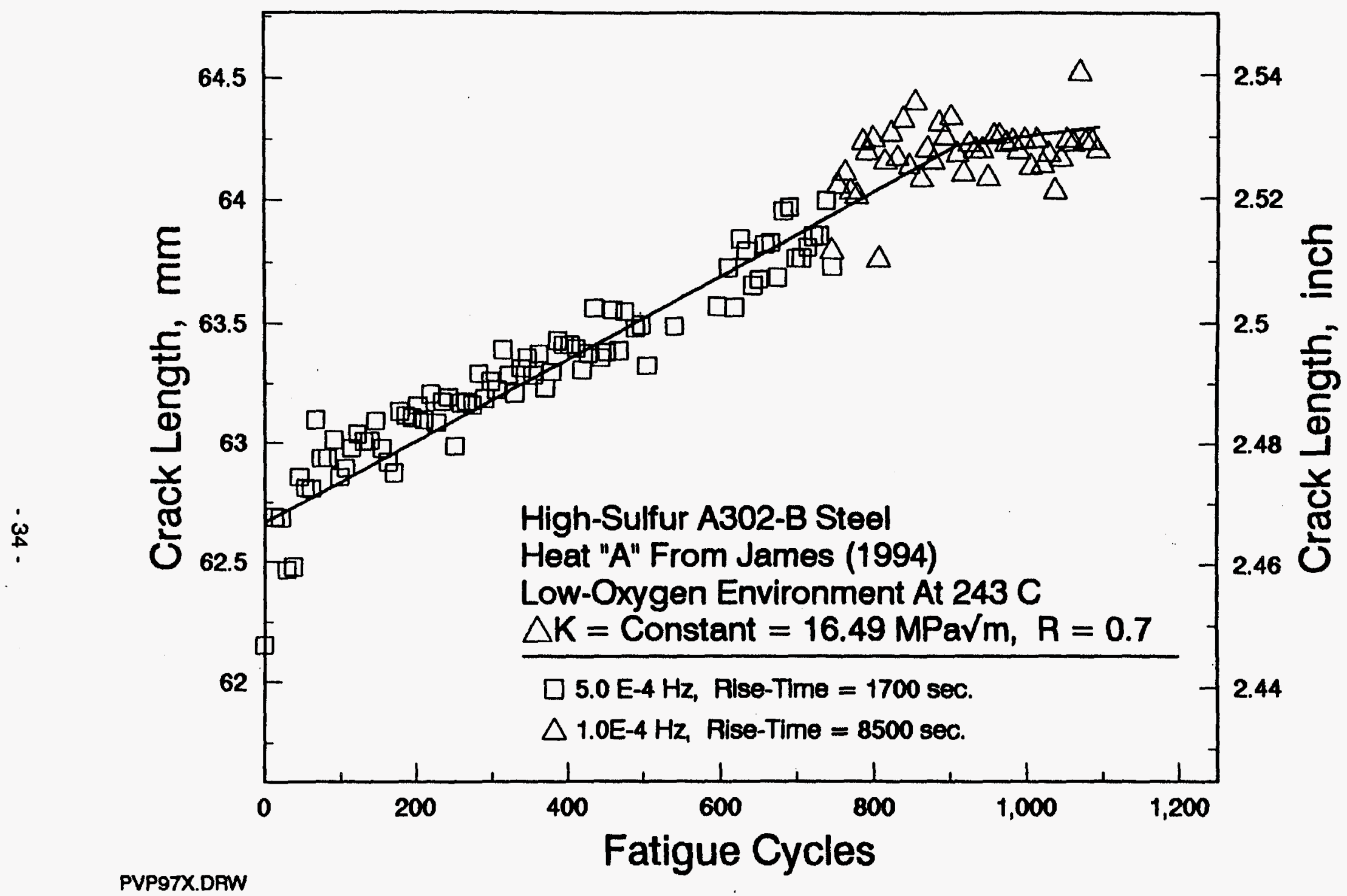

Figure 14. Crack Growth Data for High Sulfur A302B at 0.0005 and $0.0001 \mathrm{~Hz}$ Crack growth rate da/dN decreased by a factor of 4.3 early in the last portion at $0.0001 \mathrm{~Hz}$. 